NBER WORKING PAPER SERIES

\title{
ESTIMATING AND INTERPRETING \\ FORWARD INTEREST RATES: \\ SWEDEN 1992-1994
}

Lars E. O. Svensson

Working Paper No. 4871

\author{
NATIONAL BUREAU OF ECONOMIC RESEARCH \\ 1050 Massachusetts Avenue \\ Cambridge, MA 02138 \\ September 1994
}

The first draft of the paper was written while I was visiting the European I Department at the Intemational Monetary Fund. I thank the European I Department for its hospitality and productive environment. I have benefitted from discussions with and comments from Masten Blix, Peter Clark, Martin Fetherston, Lars Hörngren, Brian Hindley, Desmond Lachman, Paul Masson, Donogh McDonald, Reza Moghadam, and Svante Öberg. I thank Sveriges Riksbank for help with the data, and Marten Blix for research assistance. This paper is part of NBER's research programs in International Finance and Macroeconomics and Monetary Economics. Any opinions expressed are those of the author and not those of the International Monetary Fund or the National Bureau of Economic Research.

(C) 1994 by Lars E. O. Svensson. All rights reserved. Short sections of text, not to exceed two paragraphs, may be quoted without explicit permission provided that full credit, including $\odot$ notice, is given to the source. 
NBER Working Paper \#4871

September 1994

\title{
ESTTMATING AND INTERPRETING \\ FORWARD INTEREST RATES: \\ SWEDEN 1992-1994
}

\begin{abstract}
The use of forward interest rates as a monetary policy indicator is demonstrated, using Sweden 1992-1994 as an example. The forward rates are interpreted as indicating market expectations of the time-path of future interest rates, future inflation rates, and future currency depreciation rates. They separate market expectations for the short, medium and long term more easily than the standard yield curve. Forward rates are estimated with an extended and more flexible version of Nelson and Siegel's functional form.
\end{abstract}

Lars E. O. Svensson

Institute for International Economic Studies Stockholm University 10691 Stockholm SWEDEN and NBER 


\section{Introduction}

The purpose of this paper is to demonstrate the use of forward interest rates as a monetary policy indicator. Forward interest rates are interest rates on investment and loans that start at a future date, the settlement date, and last to a date further into the future, the maturity date. Both the estimation and the interpretation of forward rates will be discussed. Sweden during the eventful period 1992-1994 is chosen as an example.

The paper is motivated by the increased need for monetary policy indicators when flexible exchange rates have replaced fixed exchange rates. The collapse of fixed exchange rates in Europe and the widening of ERM bands mean that a well-defined intermediate target for monetary policy has been lost. In this situation, whether a new intermediate target is introduced or not, the role of indicators will be crucial, for assessing the state of the economy and the stance of monetary policy, and for deciding whether the instrument of monetary policy is on a path appropriate for achieving the goal of monetary policy. Forward interest rates should be suitable as one of the several indicators that need to be used. They should of course never be used as the only indicator.

The use of forward interest rates has long been standard in financial analysis, for instance in pricing new financial instruments and in discovering arbitrage possibilities. Although the use of yield curves is standard in monetary policy analysis in central banks and elsewhere, the use of forward interest rates for monetary policy purposes appears to be relatively recent. For instance, the Board of Governors of the Federal Reserve System, Bank of England, and Sveriges Riksbank have recently started to use forward interest rates among other indicators. ${ }^{1}$

In the absence of a full set of forward markets, implied forward interest rates need to be estimated from data on existing financial instruments, usually Treasury bills and Government bonds. For financial analysis, the estimation of forward rates is done with a number of different methods, some rather complex in order to achieve sufficient precision. For monetary policy analysis, the demand for precision is arguably less, which can be traded for increased robustness and simplicity of the estimation method. Here I will use an estimation method that is simple and robust but appears to have a precision well beyond what is needed for monetary policy purposes.

Forward interest rates will, under specified assumptions, be interpreted as indicating markel expectations of future short interest rates, inflation rates and currency depreciation rates, and used to interpret Swedish monetary policy during the period from May 1992, six months before

\footnotetext{
${ }^{1}$ See Bank of England (1993a,b), Reinhart and Klapper (1992), and Sveriges Riksbank (1993a,b). Cf. also Bank of International Settlement (1993).
} 
the krona was floated in November, until June 1994. Forward rates contain the same information as the standard yield curve. Indeed, the forward rate curve is related to the yield curve as the marginal cost curve is to the average cost curve. Forward rates present the information in a way more easily interpreted for monetary policy purposes. Whereas the yield curve can be interpreted as expected future averages of the variables in focus, the forward rate curve can be interpreted as indicating the expected future time path of these variables. Therefore forward rates more easily allow a separation of expectations for the short, medium and long term than the yield curve. This is the main advantage of forward rates. ${ }^{2}$

Section 2 of the paper defines and discusses the relations between spot rates (zero-coupon rates), yields to maturity and forward interest rate. Section 3 presents the estimation method. Readers not interested in technical details can skim these two sections. Section 4 discusses the interpretation of forward rates in general, and Section 5 discusses the interpretation of the Swedish forward rates in particular. Section 6 presents the conclusions. The Appendix reports some technical aspects of the estimation.

\section{Spot rates, yields to maturity, and forward rates}

In the absence of explicit forward markets, implied forward interest rates have to be estimated from interest rates on existing financial instruments. To compute implied forward interest rates from yields to maturity on zero-coupon bonds, spot rates, is easy. To compute implied forward interest rates from yields to maturity on coupon bonds is more complicated. Inconveniently, almost all bonds with time to maturity beyond 12 months are coupon bonds rather than zerocoupon bonds. Yields to maturity on coupon bonds are not identical to yields to maturity on zero-coupon bonds of the same maturity. Since a coupon bond can be seen as a portfolio of zero-coupon bonds of different maturities (each zero-coupon bond corresponding to a particular coupon payment), yields to maturity on coupon bonds are a kind of average of yields to maturity on zero-coupon bonds of maturities from the time of the first coupon payment to the time of the payment of the face value and last coupon. Estimating forward rates from coupon bonds can then be seen as involving two steps: first implied spot rates are estimated from yields to maturity on coupon bonds, and then implied forward rates are computed from implied spot rates.

To understand this more precisely, some algebra is needed. The algebra of spot rates, yields to maturity on coupon bonds, and forward rates is easiest if all rates are continuously compounded. ${ }^{3}$

\footnotetext{
${ }^{2}$ The analogy with average and marginal cost is exact when interest rates are continuously compounded, and when a zero-coupon yield curve is used. The analogy is approximate for coupon bond yield curves, and for an nually compounded interest rates.

${ }^{3}$ The continuously compounded spot rate $i$ and the annually compounded spot rate $i$ (both measured in percent per year) are related by $i=100\left(\exp \left[\frac{i}{100}\right]-1\right)$ and $i=100 \ln \left[1+\frac{i}{100}\right]$. See Shiller (1990) or Frage (1986) for details
} 
Let $i(t, T)$ (measured in percent per year) be the continuously compounded spot interest rate for a zero coupon bond traded at time $t$, the trade date, that matures at time $T>t$, the maturity date. Let $m=T-t$ denote the time to maturity. The term structure of interest rates at a given trade date $t$ is unambiguously represented by a graph of the spot rate $i(t, t+m)$ for different times to maturity $m$. Let $d(t, T)$, the discount function, denote the price at time $t$ of a zero-coupon bond that pays 1 krona at the maturity date $T$. It is related to the spot rate by

$$
d(t, T)=\exp \left(-\frac{i(t, T)}{100}(T-t)\right)
$$

where $\exp (x)$ denotes the exponential function $e^{x}$.

Consider now a coupon bond with coupon rate $c$ percent per year, a bond that pays a face value of 100 kronor at the maturity date but also pays an annual coupon of $c$ kronor each year up to and including the maturity date. Let the time to maturity be $m$ years. ${ }^{4}$ The present value at the trade date $t$ of a coupon payment made in year $k, k=1,2, \ldots, m$, will be $c d(t, t+k)$ and the present value of the face value paid in year $m$ will be $100 d(t, t+m)$. It follows that the price of the bond at the trade date, $P(t, t+m)$, will equal

$$
P(t, t+m)=\sum_{k=1}^{m} c d(t, t+k)+100 d(t, t+m) .
$$

For coupon bonds, yields to maturity are often quoted. The yield to maturity is the internal rate of return for the coupon bond, that is, the constant interest rate that makes the present value of the coupon payments and the face value equal to the price of the bond. Hence the yield to maturity $y(t, t+m)$ (measured in percent per year) on the coupon bond fulfills the equation

$$
P(t, t+m)=\sum_{k=1}^{m} c \exp \left(-\frac{y(t, t+m)}{100} k\right)+100 \exp \left(-\frac{y(t, t+m)}{100} m\right) .
$$

Yield curves showing the yield to maturity on coupon bonds for different maturities are frequently used to represent the term structure of interest rates. Such yield curves are an imprecise representation of the term structure of interest rates, though. First, a given yield to maturity can be seen as an average of the spot rates up to the time to maturity. The present values of the coupon payments and face value that are used to price the bond in equation (2.2) correspond to spot rates in (2.1) that generally vary with the maturity. In contrast, the present values of the coupon payments and face value that are used to price the bond in equation (2.3)

on the agebra of spot rates, yields to maturity and forward rates.

The general case when the time to maturity is not an integer is handled in the Appendix. For eemi-annual coupon payments, as in Britain and the United States, the formulas are accordingly modified (ace for instance Fage (1986)). 
are computed with a constant yield to maturity, which is hence a somewhat complicated average of the spot rates. Second, for a given term structure of spot rates, the yield to maturity for a bond with a given maturity will depend on its coupon rate, the "coupon effect." Therefore two coupon bonds that mature at the same date generally have different yields to maturity if they have different coupon rates. The reason is that, everything else equal, a higher coupon rate implies that the share of early payments increases, which gives more weight to short spot rates in the determination of the yield to maturity.

For these reasons yield curves for coupon bonds should not be used as direct representations of the term structure of interest rates. Instead spot rates should be used. ${ }^{5}$ For maturities below 12 months spot rates are directly available in the form of rates on Treasury bills, which are zerocoupon bonds. For longer maturities zero-coupon bonds are usually not available for sufficiently many maturities and in sufficiently large issues to be sufficiently liquid. Therefore, spot rates will have to be estimated from yields on coupon bonds. Also, even if there were quite a few liquid longer-maturity zero-coupon bonds, one might still want to use the additional information in the coupon bond yields.

Implied forward rates are easy to calculate from spot rates, since a forward investment with specific settlement and maturity dates can be reproduced by a sale and a purchase of zero-coupon bonds: a sale of a bond maturing on the forward contract's settlement date and a purchase of bonds of the same market value that matures on the forward contract's maturity date. The implied forward rate is the return on such a readjustment of a bond portfolio.

More precisely, let $f\left(t, t^{\prime}, T\right)$ (measured in percent per year) be the continuously compounded (implied) forward rate on a forward contract concluded at time $t$, the trade date, for an investment that starts at time $t^{\prime}>t$, the settlement date, and ends at time $T>t^{\prime}$, the maturity date. Then the forward rate is related to the spot rates according to

$$
f\left(t, t^{\prime}, T\right)=\frac{(T-t) i(t, T)-\left(t^{\prime}-t\right) i\left(t, t^{\prime}\right)}{T-t^{\prime}} .
$$

That is, the forward rate for a 1 -year investment with settlement in 4 years $\left(t^{\prime}-t=4\right.$ years) and maturity in 5 years ( $T-t=5$ years) ("the 1-year forward rate 4 years from now") is equal to 5 times the 5 -year spot rate minus 4 times the 4-year spot rate.

The instantaneous(-maturity) forward rate is the forward rate for a forward contract with an infinitesimal investment period after the settlement date, and it is defined as the limit

$$
f\left(t, t^{\prime}\right)=\lim _{T \rightarrow t^{\prime}} f\left(t, t^{\prime}, T\right)
$$

\footnotetext{
${ }^{3}$ A so-called par yield curve is an alternative way to unambiguously represent the term structure of intereat rates.
} 
In practice it can be identified with an overnight forward rate, that is, a forward rate with maturity one day after settlement. The finite-maturity forward rate $f\left(t, t^{\prime}, T\right), T>t^{\prime}$, will be the average of the instantaneous forward rates with settlement between $t^{\prime}$ and $T$,

$$
f\left(t, t^{\prime}, T\right)=\frac{\int_{\tau=t^{\prime}}^{T} f(t, \tau) d T}{T-t^{\prime}}
$$

The instantaneous forward rate can be seen as the marginal increase in the total return from a marginal increase in the length of the investment. Instantaneous forward rates and finitematurity spot rates are therefore related precisely as marginal and average cost of production, when the time to maturity is identified with quantity produced. The spot rate $i(t, T)$ at time $t$ with maturity at time $T$ is hence identical to the average of the instantaneous forward rates with settlements between the trade date $t$ and the maturity date $T$,

$$
i(t, T) \equiv \frac{\int_{t=t}^{T} f(t, \tau) d \tau}{T-t}
$$

Equivalently, the forward and spot rates fulfull the relation

$$
f(t, T) \equiv i(t, T)+(T-t) \frac{\partial i(t, T)}{\partial T}
$$

which is another standard relation between marginal and average cost, with time to maturity $T-t$ corresponding to quantity produced. Hence, when looking at spot and forward rates we shall often recognize the shapes of average and marginal curves familiar from microceconomics textbooks.

\section{Estimating forward rates}

The estimation of spot and forward rates follows McCulloch $(1971,1975)$ in fitting for each trade date a discount function (the price of a zero-coupon bond as a function of the time to maturity) to bill and bond price data, but it uses an extension of the functional form of Nelson and Siegel (1987) instead of McCulloch's original cubic spline. The cubic spline has the wellknown disadvantage that estimates of forward rates may be rather unstable, especially at the longest maturity (Shea (1984)) ${ }^{6}$

Nelson and Siegel (1987) assume that the instantaneous forward rate is the solution to a

\footnotetext{
${ }^{6}$ Dahlquist and Svensson (1994) compares the original functional form of Neleon and Siegel (1987) to the much more complex functional form of Longstaft and Schwartz (1992) on Swedish data for the anmple period December 1992-June 1993. The Nelson and Siegel functional form is moch easier to wese than the Longataff and Schmartz functional form. The additional texibility of the Longataff and Schwartz functional form is not needed for that sample period. When additional fiexibility is needed for a few trade dates in the longer ample in the present paper, the extended Nelson and Siegel functional form is chosen rince it is much eavier to use than the Longrtaff and Schwartz functional form.
} 
second-order differential equation with two equal roots. Let me simplify the notation by letting $f(m)$ denote the instantaneous forward rate $f(t, t+m)$ with time to settlement $m$, for a given trade date $t$. Then Nelson and Siegel's forward rate function can be written

$$
f(m ; b)=\beta_{0}+\beta_{1} \exp \left(-\frac{m}{\tau_{1}}\right)+\beta_{2} \frac{m}{\tau_{1}} \exp \left(-\frac{m}{\tau_{1}}\right)
$$

where $b=\left(\beta_{0}, \beta_{1}, \beta_{2}, \tau_{1}\right)$ is a vector of parameters ( $\beta_{0}$ and $\tau_{1}$ must be positive).

The forward rate in (3.1) consists of three components. The first is a constant, $\beta_{0}$, the second is an exponential term $\beta_{1} \exp \left(-\frac{m}{\tau_{1}}\right)$ monotonically decreasing (or increasing, if $\beta_{1}$ is negative) towards zero as a function of the time to settlement, and the third is a term which generates a hump-shape (or a $U$-shape, if $\beta_{2}$ is negative) as a function of the time to settlement, $\beta_{2} \frac{m}{\tau_{1}} \exp \left(-\frac{m}{\tau_{1}}\right)$. When the time to settlement approaches infinity, the forward rate approaches the constant $\beta_{0}$, and when the time to settlement approaches zero, the forward rate approaches the constant $\beta_{0}+\beta_{1}$.

To increase the flexibility and improve the fit I extend Nelson and Siegel's function by adding a fourth term, a second hump-shape (or U-shape), $\beta_{3} \frac{m}{r_{2}} \exp \left(-\frac{m}{r_{2}}\right)$, with two additional parameters, $\beta_{3}$ and $\tau_{2}$ ( $\tau_{2}$ must be positive). The function is then

$$
f(m ; b)=\beta_{0}+\beta_{1} \exp \left(-\frac{m}{\tau_{1}}\right)+\beta_{2} \frac{m}{\tau_{1}} \exp \left(-\frac{m}{\tau_{1}}\right)+\beta_{3} \frac{m}{\tau_{2}} \exp \left(-\frac{m}{\tau_{2}}\right)
$$

where $b=\left(\beta_{0}, \beta_{1}, \beta_{2}, \tau_{1}, \beta_{3}, \tau_{2}\right)$.

The function and its components is illustrated in Figure 1a. The parameters are $\beta_{0}=8.06$ percent per year, $\beta_{1}=-0.31$ percent per year, $\beta_{2}=-6.25$ percent per year, $\tau_{1}=1.58$ year, $\beta_{3}$ $=-1.98$ percent per year and $\tau_{2}=0.15$ year. (These are the estimates for Sweden for the trade date December 29, 1993.) The thick solid curve is the forward rate curve. The other curves show the four components of the forward rate curve.

The spot rate can be derived by integrating the forward rate according to (2.7). Let $i(m)$ denote the spot rate $i(t, t+m)$ with time to maturity $m$, for a given trade date $t$. It is given by

$$
\begin{gathered}
i(m ; b)= \\
\beta_{0}+\beta_{1} \frac{1-\exp \left(-\frac{m}{\tau_{1}}\right)}{\frac{m}{\tau_{1}}}+\beta_{2}\left(\frac{1-\exp \left(-\frac{m}{\tau_{1}}\right)}{\frac{m}{\tau_{1}}}-\exp \left(-\frac{m}{\tau_{1}}\right)\right)+\beta_{3}\left(\frac{1-\exp \left(-\frac{m}{\tau_{2}}\right)}{\frac{m}{\tau_{2}}}-\exp \left(-\frac{m}{\tau_{2}}\right)\right) .
\end{gathered}
$$

Fisher, Nychka and Zervos (1994) have recently provided several important extensions to McCulloch's cubic spline method. 
The discount function is then given by

$$
d(m ; b)=\exp \left(-\frac{i(m ; b)}{100} m\right)
$$

The discount function is estimated for each trade date by minimizing either (the sum of squared) price errors or (the sum of squared) yield errors. Let me first discuss minimizing price errors. Then, for given parameters the discount function is used to compute estimated bond prices according to (2.2). The parameters are then chosen so as to minimize the sum of squared errors between the estimated and observed prices of the bonds, where the observed prices of the bonds are calculated from quoted yields to maturity, coupon rates and times to maturity according to (2.3). This is the standard way since McCulloch $(1971,1975)$.

Minimizing price errors sometimes results in fairly large yield errors for bonds and bills with short maturities. This is because prices are very insensitive to yields for short maturities. ${ }^{7}$ Then it may be better to chose the parameters so as to minimize yield errors. One can also argue that since in monetary policy analysis the focus is on interest rates rather than prices, it makes sense to minimize errors in the yield dimension rather than in the price dimension. When yield errors are minimized, for given parameters the discount function is still used to compute estimated prices of coupon bonds according to (2.2). Then the estimated yield to maturity for each bond is computed by solving (2.3). The parameters are then chosen so as to minimize the sum of squared yield errors between estimated yields and observed yields.

The estimation is done with Maximum Likelihood, although Nonlinear Least Squares or the Generalized Method of Moments can also be used. Heteroskedasticity-consistent standard errors for the parameters are estimated and used with the so called delta method to obtain confidence intervals for spot and forward rates. Details of the estimation method are given in the Appendix.

In some cases minimizing price errors results in quite good fits of yields. In many cases, however, the yield fit for short maturities appears less than satisfactory, and minimizing the yield errors then gives a nuch better fit, usually with only a minor deterioration of the price fit.

In most cases the original Nelson and Siegel model gives a satisfactory fit. In some case when the term structure is more complex the fit of the original Nelson and Siegel model is unsatisfactory. Then the extended model improves the fit considerably.

As an example of an estimation result, see Figure $1 b$. It shows the estimate for Sweden for the trade date December 29, 1993. The estimation is done with minimized yield errors, for the exteuded Nelson and Siegel model. The squares show the observed marginal lending rate and observed yields to maturity on Treasury bills and Government benchmark bonds, plotted

\footnotetext{
${ }^{7}$ Recall that the elasticity of the price with respect to one plus the yield is equal to the duration of a bond (the present-value weighted average maturity of coupon payments and face value).
} 
against the maturity date. ${ }^{8}$ All rates are annually compounded. The pluses show the coupon rates for the bonds (the Treasury bills and the marginal lending rate have zero coupons). The dashed curve shows the estimated spot rate curve, the zero-coupon rates. The error bars show 95 percent confidence intervals. Dots with error bars show the estimated yields to maturity with 95 percent confidence intervals (the estimated yields are on the spot rate curve for zerocoupon bonds but are generally not so for coupon bonds, since yields to maturity on coupon bonds generally differ from yields to maturity on zero-coupon bonds). The fit is good, and the error bars are hardly visible. The solid curve shows the estimated (instantaneous) forward rate, plotted against the settlement date, with error bars showing 95 percent confidence intervals. The horizontal dashed line is the asymptote for the spot and forward rate (the parameter $\beta_{0}$ ). The root mean squared yield error for this estimation is 0.03 percentage points per year, the root mean squared price error is 0.16 kronor for a bond with face value 100 kronor.

In this case the spot rate curve has a $U$-shape similar to the standard shape of average cost curves in microeconomics textbooks. Consequently, the forward rate curve has a shape similar to the standard shape of marginal cost curves. We see that the spot and forward rate curves start at the same point for zero time to maturity (the overnight rate), then while the spot rate is decreasing in the time to maturity the forward rate is below the spot rate. The forward rate curve cuts the spot rate curve in the latter's minimum, and when spot rates are increasing in the time to maturity the forward rate is above the spot rate.

The forward rate has a more complex shape on December 29,1993 , than normally, with a conspicuous kink for about 3 months settlement. Therefore, the fit with the original Nelson and Siegel functional form is unsatisfactory, and the extended variant results in a much better fit. For details about the fit with the original form and for minimized price errors, see the Appendix.

\section{Interpreting forward rates}

Under the assumption that the forward term premium is negligible, forward rates can be interpreted as expected future spot rates. The forward term premium is the expected excess return on a forward investment, that is, the excess of the forward interest rate over the spot rate that is expected on the forward contract's trade date to rule on the forward contract's settlement date. The assumption of zero term premia, the so called expectations hypothesis for the term structure of interest rates, have been frequently tested and often been rejected.9 ${ }^{9}$ On the other

\footnotetext{
-The marginal lending rate was, through May 1994, the overnight rate at which banks could borrow reserves from the Riksbank. It can be seen 28 the Rikbbank's monetary policy instrument. Arbitrage by banks implied that the interbank overnight rate would be close to the margin al lending rate.

From June 1, 1994, the Riksbank uses a system similar to that of Bundesbank, in that the repo rate, bounded by a floor (the deposit rate) and a ceiling (the lending rate) erves at the policy intrument.

'See Shiller (1990) and Campbell and Shiler (1991). Fama and Blise (1987) cannot, however, reject the expectations hypothesis for some combinations of settlement and maturity that are highly relevant for monetary
} 
hand, attempts to estimate forward term premia have resulted in rather small estimates. The issue is complicated by the fact that there are three related but distinct term premia which are sometimes confused: the forward term premium, the holding period term premium, and the rollover term premium. ${ }^{10}$ Furthermore, the combinations of settlement and maturity that are examined in the literature are often not the combinations that are most relevant for monetary policy. Upward-sloping yield curves, that is, long rates being higher than short rates, are sometimes taken as implying positive term premia. That implication is not correct if short interest rates have been rising over the sample period, which is the case with many samples. See Svensson (1993c) for further discussion of these points, for references to the literature, and for empirical results on McCulloch's (1990) long sample of U.S. data that indicate that average term premia have been negligible even though the yield curve has on average been upward sloping. ${ }^{11}$

In the rest of the paper forward term premia will be disregarded, except when they are explicitly discussed in section 5.7 below. The (instantaneous) forward rate curve can then be interpreted as indicating the expected time path of future overnight rates. Since in Sweden the overnight rate by arbitrage is close to the Riksbank's monetary instrument, the marginal lending rate before June 1, 1994, and the repo rate after that date, the forward rate curve can also be interpreted as indicating the expected time-path of the future marginal lending/repo rates and hence, in that sense, the expected time path of future monetary policy.

Under the assumption that the inflation risk premium is zero, the Fisher equation holds. That is, the expected inflation equals the difference between the nominal spot rate and the real spot rate. Then, conditional upon an assumption of a given expected future short real interest rate, the expected inflation rate at a give future date equals the difference between the expected future short nominal and real rates at that future date. Since the forward rate indicates expected future short rates, the gap between the forward rate curve and the assumed future real short rate can be interpreted as indicating the expected time path of future inflation rates.

Under the assumption that the foreign exchange risk premium is zero, that is, that uncovered interest parity holds, the difference between the domestic and foreign spot rate indicates the expected average rate of depreciation of the home currency relative to the foreign currency during the period to maturity. Similarly, the difference between the domestic and foreign forward rate curves indicates the expected time path of the future currency depreciation rates.

Uncovered interest parity is usually rejected in empirical tests. On the other hand, estimates

policy, namely settlement in a few years and maturity one year later.

${ }^{10}$ The forward term premium is the excess of the forward rate over the expected future spot rate. The holding period term premium is the excess of the expected bolding period return on a long bond over the epot rate for the (usually rather short) holding period. The rollover term premium is the exceas of the yield to maturity of a long bond over the expected return on rolling over a short bond to the long bond's maturity date. See Shiller (1990) for details.

"A theoretical discussion of the determinants of term, inflation and foreign exchange risk premia is provided in Svensson (1993d). 
of foreign exchange risk premia have usually been small (see Hodrick (1987) and Marston (1993) for surveys).

In the rest of the paper the forward term premium, the inflation risk premium and the foreign exchange risk premium are assumed to be negligible (except when they are explicitly discussed in section 5.7). Forward interest rates are consequently interpreted as indicating the expected time path of future short rates, future monetary policy, future inflation rates (conditional upon an assumption of future short real rates) and future currency depreciation rates. Even if the premia are not negligible, as long as they are stable shifts in the curves still indicate changes of the variables in focus.

\section{Interpreting Swedish forward rates}

\subsection{Time series}

Figure 2a shows a weekly time series of the marginal lending/repo rate and estimated spot rates for 6-month, 1-year, 2-year, 5-year and 10-year maturities, for the trade dates May 13, 1992June 15, 1994. Figure $2 b$ shows the marginal lending/repo rate and (instantaneous) forward rates for 6-month, 1-year, 2-year, 5-year and 10-year settlements. Figures $3 a$ and $3 b$ show 3dimensional graphs of these spot and forward rates; hence Figures $2 \mathrm{a}$ and $2 \mathrm{~b}$ show intersections along corresponding maturities/settlements.

The September and November 1992 crises show up as peaks of the marginal lending rate. ${ }^{12}$ Estimates of forward rates are very unreliable during the September crises and its immediate aftermath, since Treasury bill spreads were very wide and the quotes were in all likelihood very un reliable. This shows up in large fluctuations in the forward rates from September 16 and the next few weeks, as can be seen in Figure $2 b$. Figure $2 b$ also reveals that long forward rates reached their May 1992 levels again only as late as August 1993.

After the Board of Governors of the Federal Reserve System raised the Federal funds' rate on February 4, 1994, forward rates increased dramatically through the spring of 1994 . This increase is discussed in some detail in section 5.7 below. After the increase, forward rates are back at their early 1993 levels.

Figure $\{$ shows a time series of forward rates and the krona/deutsche mark exchange rate for the period after the krona was floated, starting December 9, 1992 (the exchange rate is plotted from November 18, the day before the krona was floated). The exchange rate has displayed considerable volatility, and the krona has depreciated from 3.76 kroner per mark before it was floated to a maximum exceeding 5 kronor per mark in September 1993, an almost 35 percent increase in the exchange rate (about a 25 percent loss in the mark value of the krona). The

\footnotetext{
${ }^{12}$ See Hörngren and Lindberg (1993) for an account of the two crises.
} 
marginal lending rate and the short forward rates (up to 2-year settlement) displays a fairly consistent downward trend. Long forward rates (10-year settlement) first increase to a maximum at the end of March, which coincides with a considerable depreciation of the krona. Then came a period of decreasing long forward rates and an appreciating krona which lasted into June 1993 , followed by a depreciation of the krona and some decrease and then a flattening out of long forward rates. Towards the end of 1993 and in early 1994 forward rates fell and the krona appreciated somewhat.

\subsection{Selected dates before and after the crises}

Figure 5a shows a time series for the marginal lending/repo rate, and the forward rate curve for selected trade dates before, between, and immediately after the two crises in September and November 1992. The dotted curve shows forward rates on the trade date July 1, 1992. The marginal lending rate was a bit above 12 percent (annually compounded; the simple rate was 11.5 percent ${ }^{13}$ ), and was according to the forward rate curve expected to fall by 2 percentage points during the next 2 years and to approach 9 percent after 1995. The curve with short dashes shows forward rates on August 12, one month before the September crises started. The marginal lending rate was then 0.5 percentage points higher, and expected to rise to 13.5 percent within the next few weeks, and thereafter eventually fall to 9.5 percent. It appears that the September crises and its increase in the marginal lending rate was to some extent anticipated by the market.

The curve with long dashes refers to the trade date October 28,1992 , three weeks before the November crisis. The marginal lending rate was then expected to fall from about 13.4 percent to about 10.5 percent, and there was no obvious anticipation of further increases in the immediate future. The solid line refers to December 9, 1992, 3 weeks after the krona was floated. The marginal lending rate was then back at a bit above 12 percent, expected to fall rather quickly by 3 percentage points during 1993 and then increase to 10 percent, 1 percentage point higher than the long-run level on July 1, 1992.

Since reliable market quotations of real interest rates are not available for Sweden, ${ }^{14}$ an explicit assumption of expected future short rates need to be made in order to infer inflation expectations. Britain has a large and reasonably active market for indexed bonds. British real rates have usually fluctated between 3 and 4 percent. Here I will mostly assume an expected

\footnotetext{
${ }^{13}$ The marginal lending rate is normally quoted as a simple rate. For comparison across maturities, rates have to be compounded at the ame frequency. For instance, continuously compounded or annually compounded rates can be used. Here anuually compounded rates are used in all graphs. For a simple overnight interest rate of 11.5 percent per year, the corresponding annually compounded rate is about 0.7 percentage pointe per year higher. $A$ simple rate $i$ percent per year with maturity $m$ years is related to the annually compounded rate $i$ percent per year according to $1+\frac{i}{100} m=\left(1+\frac{i}{100}\right)^{m}$. For the overnight rate, that is, for very small $m$, the simple rate $i$ is cloce to the continuoualy compounded rate $i$.

${ }^{24}$ The Debt Office made a small issue of a 20-year indexed bond in April, 1994. See further discussion in section 5.7.
} 
future Swedish short real interest rate of 4 percent, although, as will be seen below, I will allow for the possibility that the expected future real rate was lower at the end of 1993 and that it rose considerably during the spring 1994. Thus, let me here assume that the expected future short real rate in December 1992 was 4 percent during 1995 and later. Then the expected inflation rate for the period after 1995 was about 6 percent per year in December 1992, 1 percentage point per year higher than in May 1992.

\subsection{The period after the krona was floated}

Figure $5 b$ shows the marginal lending rate and forward rates for selected dates for the period after the krona was floated, December 1992-June 1994. The dotted curve, for the trade date December 9,1992 , is the same as the solid curve in Figure $5 \mathrm{a}$. The curve with short dashes refers to trade date February 25, 1993. The marginal lending rate had then been lowered from just above 12 percent to just above 10 percent ( 9.5 percent expressed as a simple rate). This was faster than was expected on December 9 , since the marginal lending rate had fallen below the forward rate curve of December 9. The marginal lending rate was expected to fall further by 2 percentage points until mid 1994, and thereafter rise to reach 11 percent after year 2000, 1 percentage point higher than on December 9 . The forward rate curve had hence tilted considerably compared to December 9.

The marginal lending rate had been lowered by 0.75 percentage point on February 5 , a larger change than previous steps of 0.5 percentage points. As can be seen in Figure 4 , the krona started to depreciate rapidly after mid February, and forward rates increased somewhat. It is possible that the high forward rates and the depreciating krona reflected expectations that the Riksbank was embarking on a more expansionary monetary policy with a higher inflation rate.

The Riksbank had in January announced an inflation target, namely that the inflation rate during 1995 onwards rate should be 2 percentage points, with a tolerance interval of \pm 1 percentage point. Assuming an expected real rate of 4 percent in 1995 onwards, the expected inflation rate was about 4.5 percent per year for 1995 and increasing up to 7 percent per year for year 2000. According to this measure, the inflation target was far from credible. ${ }^{15}$

Could forward rates increasing in the time to settlement be interpreted as something else than an expected upward-sloping time path of future inflation rates? One possibility is of course that there is a forward term premium that is rapidly rising with the time to maturity. There seems to be no reason why the forward term premium should suddenly become rapidly increasing in the time to maturity, though, and existing empirical evidence indicates that on average the term

\footnotetext{
${ }^{13}$ After the British pound was floated on September 16, 1992, British long forward rates also increased dramatically, as documented in Bank of England (1993a,b) and Svensson (1993c). British long forward rates did not reach pre-September 1992 levels nntil almost 12 months later.
} 
premia are small. Alternatively, an expected increase in overnight rates might reflect a return to normal short real rates if current short real rates were abnormally low. Swedish short real interest rates were hardly abnormally low in February, though, and future expected short real rates much above the assumed 4 percent seems unlikely, at least to me. Could the upward-sloping forward rate curve be interpreted as an expected future increase in the marginal lending rate due to future monetary contraction because of expected future inflation? Hardly. If the central bank is expected to react to higher inflation with a monetary contraction, this should be incorporated into price-setting behavior, in which case the higher inflation and resulting contraction would not occur, and hence should not be expected to occur. Instead it seems that the expected increase in overnight interest rates must be interpreted as an expected accommodation of the central bank to a situation of higher inflation, higher money growth, and higher interest rates due to lower demand for real money balances.

On February 25 the Riksbank made an announcement that emphasized the inflation target and suggested that market expectations of lower future marginal lending rates were exaggerated. The Riksbank also intervened on the Treasury bills market in order to increase short interest rates. During the next two weeks the krona appreciated (Figure 4), and long forward rates fell considerably, more than short forward rates (Figure 4). The forward rate curve tilted back to the position showed by the curve with long dashes in Figure $5 \mathrm{~b}$, for the trade date March 8 , 1993. Inflation expectations fell by about 0.5 percentage points for 1995 , by about 1 percentage point for year 2000 and after (under the assumption that the expected future short real rate did not change).

This gain in inflation target credibility vanished, however, when a parliamentary crisis for the government began on March 10. The krona depreciated and long forward rates increased towards the end of March to their highest level during the whole sample period, well above 11 percent (Figure 4).

Later in April long forward rates fell (Figure 4), and in the third week of April the Riksbank lowered the marginal lending rate after having held it constant for more than two months. Long rates continued to fall and the Riksbank cautiously lowered the marginal lending rate gradually during the rest of the spring. The curve with dashes and dots in Figure $5 \mathrm{~b}$ shows the forward rate curve on June 30, beginning at the marginal lending rate just above 9 percent, falling to 7 percent at the end of 1994 and then rising to 9.5 percent in year 2000. Under the assumption of a 4 percent expected real rate for 1995 onwards, inflation expectations for 1995 were almost within 3 percent per year, the upper target limit, although for later years expected inflation clearly exceeded the target interval.

The thin solid curve in Figure $5 \mathrm{~b}$ shows the forward rate curve 6 months later, on December 29,1993 . The marginal lending rate had then been lowered to 8 percent ( 7.5 percent expressed as a simple rate). The marginal lending rate was expected to fall very quickly by more than 1 
percentage point in the new year, consistent with speculation in the media that the Riksbank under the new Governor from January 1, 1994, would lower interest rates rapidly. Under the assumption of a 4 percent expected future real rate, inflation expectations were below 2 percent per year for 1995, hence within the target interval between 1 and 3 percent per year. Inflation expectations exceeded the 3 percent ceiling for 1998 and later years, though.

Bank of England (1994) reports that British real forward rates fell between October 27, 1993, and February 2, 1994, by more than 0.5 percentage points for some settlement dates. Therefore, expected future Swedish real rates may also have fallen during that period, perhaps by about the same magnitude. An assumption of an expected future real rate of 3.5 percent would then result in inflation expectations about 0.5 percentage point per year higher than those reported above.

As argued below in section 5.7, with hindsight it appears that it is possible that forward rates were too low at the end of 1993 because of portfolio effects or perhaps because of a "bubble" in bond rates. This means that inflation expectations may have appeared misleadingly low at the end of 1993 and in early 1994.

The thick solid curve shows the forward rates on June 15, 1994. The large shift in the forward rates during the spring is further discussed in section 5.7.

Figure $5 \mathrm{~b}$ may be contrasted with Figure $5 c$, which shows spot rates for the same trade dates as in Figure 5b. The considerable increase in long forward rates between December 9 and February 25 does not correspond to any increase in long spot rates. Short spot rates fall and long spot rates are roughly constant. We recall from (2.7) that long spot rates are an average of forward rates for the whole period up to the maturity date. Then, if short spot rates fall, but long spot rates remain constant, it must be that forward rates with settlement far into the future increase. Else the average could not remain constant.

Although both spot and forward rates in principle contain the same information, forward rates make it more easy to infer expected future short rates and filter out expected short rates in the immediate future; since spot rates indicate expected average future short rates whereas forward rates indicate the precise expected time path of future short rates.

\subsection{Comparison with German rates}

Figure 6a shows a time series of German and Swedish rates: German overnight rates, Swedish marginal lending/repo rates, and both countries' forward rates, for settlement in 2, 5 and 10 years. The period is December 1992-June 1994. For instance, the two thin solid curves show forward rates with 2-year settlement. The German curves are always below the corresponding Swedish ones.

Figure $6 b$ shows German (thin curves) and Swedish (thick curves) forward rates for four 
selected dates: December 9, 1992, June 30 and December 29, 1993, and June 15, 1994. The Swedish rates are higher than the German ones. The difference between the forward rates decreased during 1993, but it increased again during spring 1994. We see in Figure $6 \mathrm{~b}$ that Bundesbank has lowered the short interest rate roughly as expected by the market half a year earlier: each new forward rate curve starts out on or near the previous curve.

\subsection{Exchange rate expectations}

The difference between Swedish and German forward rates can be interpreted as the expected future time path of the krona depreciation rate relative to the mark. Equivalently, the difference between Swedish and German spot rates can be interpreted as the average krona depreciation rate relative to the mark up to maturity. Given the current exchange rate the expected future exchange rates can then be calculated. Figure 7 shows the actual krona/mark exchange rate since November 18,1992, the day before the krona was floated, and the expected future exchange rate as of the same trade dates as in Figure $6 \mathrm{~b}$. The krona has depreciated much more rapidly than was expected on December 9, 1992. In spite of the large depreciation that had occurred by June 15, 1994, further depreciation was expected.

\subsection{Comparison with other countries}

Figure $8 a$ compares forward rates for Sweden, Britain, France, Germany and the United States, for June 30 and December 29, 1993, and June 15, 1994. On June 30,1993, long forward rates for France, Germany and the United States clustered together, Swedish forward rates were about 2 percentage points higher, and British forward rates were somewhat below the Swedish ones. In the spring of 1993 there had been an even clearer pattern of a clustering into two categories, Britain and Sweden with similar higher long forward rates, and France, Germany and the United States with similar lower long forward rates. ${ }^{16}$ By December 29, 1993, Britain had joined the low rate group with long forward rates converging at 7 percent. Sweden remained alone with almost 1.5 percent higher long rates than the rest. Britain's short rates were expected to rise, and Sweden's to fall, so that they were expected to be equal at about 6 percent in 1996, after which Sweden's rates were expected to increase more rapidly than Britain's.

By June 15, 1994, the forward rates had shifted up for all countries, but by more for Britain and Sweden. The British forward rates now again fell between Sweden's and the other countries.

Figure 86 shows corresponding spot rates. Britain's convergence to the low-rate group by Decomber 29, 1993, is not apparent from the spot rates. A comparison between the spot and forward rates give several good examples of different combinations of average and marginal

\footnotetext{
${ }^{16}$ See Svensson (1993b) for a more detailed discussion of forward rates and monetary policy in these countries for the period between September 1992 and September 1993
} 
curves.

\subsection{The interest rate increase during spring 1994}

On February 4, 1994, the Board of Governors of the Federal reserve system raised the Federal funds rate for the first time in 5 years. This marked the beginning of a period of rising bond rates in United States and Europe, a period that has continued through the spring and is still going on at the time of writing this (June 1994). The dramatic rise in spot and forward rates is apparent in Figures $2 a$ and $2 b$ for Sweden, and in Figures $8 a$ and $8 b$ for the other countries. From Figures $8 a$ and $8 b$ it appears that spot and forward rates have increased more for Britain and Sweden than for France, Germany and the United States. In Figure $6 \mathrm{~b}$ we can see that between December 29,1993, and June 15, 1994, the forward rate with settlement in January 1998 increased by almost 2 percentage points for Germany, and by more than 3 percentage points for Sweden.

Interpreting this increase in spot and forward rates is a considerable challenge. Throughout the spring the media have been full of competing explanations. Here I shall focus on the rise in Swedish forward rates. As discussed above, the nominal forward rate can be seen as the sum of three components: the expected future short real interest rate, term and inflation risk premia, and the expected future inflation rate (see Svensson (1993c,d) for details). The issue at hand is then to try to judge how the total increase in Swedish forward rates can be decomposed into changes in these components, and especially how much of the total change is an increase in infiation expectations. Let me discuss each component in turn.

\subsubsection{Expected future real interest rates}

Have expected future real interest rates increased? This question is difficult to answer in the absence of markets for indexed bonds. The only country with a reasonably large and active market for indexed bonds is Britain. Bank of England (1994) reports that between February 2 and May 4, 1994, real forward rates increased by about 1 percentage point at the short end (settlement in about 2 years), and about 0.5 percentage point at the long end (settlement in 8 years and more). During the same period British nominal forward rates increased by about 3 percentage points at the short end, and about 1.5 percentage points at the long end. Thus, for Britain the increase in real forward rates was roughly a third of the increase in nominal forward rates. In May 1994 the level of British real forward rates was between 3.5 and 4 percent.

The real forward rate equals the expected future real spot rate plus a real term premium. The increase in British real forward rates may thus consist of an increase in both the expected future spot rate and the real term premium. Let me for simplicity interpret the increase in real forward rates as an equal increase in expected future real spot rates, although later I shall allow 
for the possibility that an increase in the real term premium is included.

As a first approximation, one might assume that the increase in expected future Swedish real rates was about of the same magnitude in Sweden as in Britain. Could expected future Swedish real rates have increased more than British rates did? One possibility is of course that the large Swedish budget deficit might induce higher real rates on Swedish government bonds than in other countries, due to a portfolio effect because of a large supply and an inelastic demand (assuming there is yet no default premium on Swedish bonds). On the other hand, Swedish bonds are still such a small share of world portfolios that demand should be rather elastic. Even though Swedish real rates may be higher than British ones, there is also no clear reason why the margin should have increased during the spring.

The Swedish Debt Office issued an indexed bond in mid-April, 1994, a zero-coupon bond with 20 year maturity. The bond was bought at a real rate of 4 percent per year. Although this rate is consistent with the assumption of a 4 percent real rate used above in this paper, the rate on this long bond does not of course indicate much about the real rate for the next few years, since it is the average real rate for the next 20 years. Also, the issue was not large, the Debt Office did not issue all it had planned to issue (since it did not accept rates above 4 percent), and no active secondary market has developed.

In conclusion, I find it reasonable to assume that Swedish expected future real rates may have increased by 1-1.5 percentage points during the spring (possibly including an increase in the real term premium), and that the expected future real rate may be about 5 percent after the spring (possibly including a real term premium) rather than $3.5-4$ percent before the spring.

\subsubsection{Term premia}

Could term and inflation risk premia have increased during the spring? Let me first discuss term premia. A (forward) term premium is the excess of the forward rate over the expected future short spot rate. A positive (negative) term premium implies that the forward rate overestimates (underestimates) the expected future spot rate.

When nominal and real forward rates are compared, as can be done for Britain, the difference between the nominal and real forward rate equals the sum of the difference between the expected future nominal and real spot rate and the difference between the nominal and real term premium. ${ }^{17}$ If both term premia increase by the same magnitude, the increases cancel. Above I have disregarded the real term premium and interpreted the increase in British real forward rates as an increase in expected future real spot rates, which led to the assumption of an increase in expected real Swedish spot rates of 1-1.5 percentage points. Alternatively, I could

\footnotetext{
"The nominal (real) term premium is the excess of the nominal (real) forward rate over the expected future nominal (real) spot rate.
} 
have assumed that this increase included a possible increase in the real term premium. If the nominal term preminm increases by the same amount as the real one, no bias results. Thus, in the case when the term premia increase by the same magnitude has already been implicitly handled above.

It remains to consider the possibility that the nominal term premium has increased more than the real one. According to standard portfolio theory (see Svensson (1993d)) the nominal (real) term premium is proportional to the negative of the covariance between the future nominal (real) spot rate and the nominal (real) return on the market portfolio (or nominal (real) consumption, depending upon which asset-pricing model is assumed). If the variability of the nominal spot rate has increased more than the variability of the real rate, it is possible that the covariance for the nominal rate has increased in magnitude more than the covariance of the real rate. To judge whether that has happened during spring 1994 requires additional research, though.

A popular explanation, frequently mentioned in the media, for the interest rate movements during the spring is that some investors (notably so-called hedge funds) during 1993 took large long positions in long American and European bonds, financed by short borrowing, in the expectation of falling long rates and corresponding capital gains. Such large open positions in long bonds would depress long spot rates, and also lead to low forward rates and perhaps negative term premia. If so, forward rates at the end of 1993 would have underestimated expected future spot rates. Alternatively, some investors expecting falling long rates is consistent with these investors expecting low future short rates and also anticipating that the market will eventually share those expectations. In that case average expectations of future spot rates were exceptionally low at the end of 1993 . The Federal Reserve's increase in the Federal funds rate on February 4 would then indicate a shift to a new situation with rising short rates, and hence rising long rates. The investors with long positions in long bonds would then attempt to close their positions, with rising bond rates as a result. Although this argument may help to explain why US long rates would go up, it is not clear why European long rates would follow. One possibility is that investors for no obvious reason also suddenly expected rising European short rates, another possibility is that losses on American investments forced investors to reduce exposure in European investment, a third possibility is that some long investment in Europe was financed with short borrowing in the United States (in which case one perhaps should have seen a significant appreciation of the dollar against European currencies during the spring).

According to this explanation term premia (or expected future short rates) were perhaps too low at the end of 1993 , whereas they have been corrected during the spring or perhaps even become too high by now. This explanation can also be interpreted as referring to a bond "bubble" at the end of 1993, a situation when bond rates lose contact with fundamentals and due to bandwagon effects fall beyond what is warranted by fundamentals. The Federal Reserve's increase in the Federal funds rate would then have burst the bubble. The events during the 
spring might then either be interpreted as a return to fundamentals, or perhaps the start of a period with a "reversed" bubble, a situation when bond rates lose contact with fundamentals but become too high rather than too low.

An interesting possibility is that Fed's maintaining a very low Federal funds rate for so long, and some European central banks' eagerness to lower short interest rates, may have fueled such a bond bubble during 1993, whereas higher short rates might have dampened such a bubble or even prevented it from occurring.

Whether or not this explanation is relevant to the interest rate movements in Europe and United States, I do not see that it can rationalize why rates in Britain and Sweden increased much more than rates in France, Germany and United States.

\subsubsection{Inflation risk premia}

Could inflation risk premia have increased during the spring? The inflation risk premium is the excess of the difference between expected future nominal and real short spot rates over the expected future inflation rate. The inflation risk premium depends on the perceived variability of future inflation; according to standard portfolio theory it is proportional to the negative of the covariance between inflation and the real return on the market portfolio (or real consumption). Increased uncertainty about inflation may imply an increased magnitude of the covariance, and hence a larger inflation risk premium (if the covariance is negative).

Commentators sometimes for some reason seem to imply that it is better if an increase in noninal interest rates is due to an increased inflation risk premium than to an increase in expected inflation (expected inflation interpreted as the perceived mean of inflation). This cannot be right. An increased inflation risk premium is of course by itself a problem for a monetary policy with price stability as a goal.

An increase in the variability of inflation without an increase in expected inflation is an example of a so-called mean-preserving spread. A mean-preserving spread for inflation requires that the probability of both high and low inflation increases so as to leave the mean unchanged. In practice, it seems more likely that increased variability of inflation corresponds to an increased probability of high inflation and a constant or reduced probability of low inflation. That is, an increased variability of inflation goes with an increased mean (this point is made by Bank of England (1994)). Therefore, in many situations an increased inflation risk premium would also imply increased expected inflation. An increase in the inflation risk premium is therefore a problem for monetary policy for two reasons, since it indicates both an increased variance and an increased mean of inflation. When evaluating monetary policy, for practical purposes the distinction between the inflation risk premium and expected inflation may be less important. ${ }^{18}$

\footnotetext{
10 A rather imperfect measure of inflation uncertainty, the standard deviation of answers to Swedish inflation
} 


\subsubsection{Inflation expectations}

Let me finally consider the remainder, the expected future inflation rate. Above I noted that the Swedish forward rate with settlement in 1998 increased by more than 3 percentage points between December 1993 and June 1994. Suppose expected future real rates increased by 1 . 1.5 percentage points, possibly including an increase in term premia. That would leave 1.5-2 percentage points to be explained by an increase in the expected inflation rate and the inflation risk premium. Suppose the inflation risk premium increased by as much as 0.5 percentage point; that would leave 1-1.5 percentage points increase in inflation expectations. This is still a sizable increase in inflation expectations.

Let us look at levels instead. Suppose that we accept the assumption that in June 1994 the expected future real rate was as high as 5 percent. This is a rather high real rate, but we may interpret it as also including possible term premia. In June, the nominal forward rate with settlement in 3-5 years was a bit above 10 percent. Subtracting the expected future real rate gives inflation expectations of about 5 percent per year, possibly including an inflation risk premium. Is that a reasonable result?

It may be illuminating to consider the result of a survey of inflation expectations (Aragon (1994)), where the largest domestic and foreign investors on the Swedish bond market are asked each quarter about their inflation expectations for the next 2 and 5 years. From this the investor's implicit expectations for years 3-5 can be computed. The thick curve in Figure 9 shows the result. In mid February and mid May 1994, inflation expectations for years 3-5 were 4.3 and 4.6 percent per year, respectively. This is clearly a small increase compared to the increase of 1-1.5 percentage points above. Although the inflation expectations in the survey generally move in the same direction as the forward rates, they fluctuate much less. On the other hand, the survey inflation expectations in May are rather close to the 5 percent per year inflation expectations calculated from the June forward rate. The survey results thus support the view that forward rates were too low in early 1994. The large increase in estimated inflation expectations reported above may be too large, not primarily because forward rates were too high at the end of the spring, but rather because they were too low at the beginning of the spring.

In summary, the conclusion I would like to draw is that nominal forward rates were probably too low in early 1994, with either negative term premia or very low expected future spot rates. Disregarding premia and assuming a 3.5-4 percent real interest rate then may have resulted in too low an estimate of inflation expectations. With hindsight, the apparent reduction of inflation expectations at the end of 1993 was probably to a considerable extent an illusion. The increase in nominal forward rates during the spring has corrected this, but the forward rates have increased much more. Part of the increase in nominal rates is explained by an increase in

expectations survey further discussed below (Aragon (1994)), actually fell between February and May 1994. 
expected future real rates. This does not explain the whole increase in nominal forward rates, though, but inflation expectations a few years ahead have increased as well, and possibly also the inflation risk premium. In a situation with considerable real rate movements, it would of course be particularly useful with reliable market quotes on indexed bonds of different maturities. In the absence of reliable market quotes on real interest rates, an assumption that the expected future real spot rate has increased to 5 percent in June 1994 may be reasonable. This results in an expected future inflation rate in June 1994 of about 5 percent per year for 1997 onwards.

\section{Conclusions}

With flexible exchange rates, monetary policy in Europe will have to rely more on indicators than previously under fixed rates, especially since it will most likely be difficult, at least for some time, to find appropriate and reliable intermediate targets for monetary policy. Several different indicators will have to be used. One of the potential indicators, the (implied) forward interest rate curve, can be used to indicate market expectations of the time-paths of future short interest rates, monetary policy, inflation rates and currency depreciation rates.

The forward rate curve contains the same information as the spot rate curve, but it presents the information in a way that makes it easier to interpret for monetary policy purposes. Thus the forward rate curve separates market expectations for the short, medium and long term more easily than the spot rate curve. Since monetary policy measures have effects with "long and variable lags," looking beyond the short term is often necessary in monetary policy analysis. Using long spot rates or long bond yields instead of long forward rates can give a misleading impression, since long spot rates and long bond yields include expectations of interest rate movements in the short term. In long forward rates, expectations of interest rate movements in the short term have been filtered out.

The paper has demonstrated both the estimation and interpretation of forward rates. The estimation has been done by an extended version of Nelson and Siegel's (1987) functional form. The extended version gives a very good fit in the relatively few cases when the original version is insufficient.

The interpretation of forward rates has been demonstrated in a fairly detailed study of Swedish forward rates during the eventful period May 1992-June 1994. The study has revealed that the September 1992 increase in the marginal lending rate to some extent was anticipated by the market, and that long forward rates (as in Britain) rose considerably after the currency was floated. It is possible that this indicated increased long-run inflation expectations in reaction to a faster than expected lowering of the marginal lending rate during December 1992-February 1993. Movements in forward rates and inflation expectations in February and March 1993 are consistent with likely reactions to Riksbank actions and the crisis in parliament. The study has 
also revealed that long forward rates did not reach their May 1992 levels until August 1993. The dramatic increase in forward rates during the spring 1994 has been discussed in some detail. The conclusion is that forward rates may have been artificially low at the end of 1993 and in early 1994, due to possible portfolio effects and perhaps even a temporary bubble in long bond rates, resulting in too low estimates of inflation expectations. The rise in forward rates during the spring 1994 appears to have been caused by both rising expected future real rates, rising inflation expectations, and possibly also rising inflation risk premia.

The paper's maintained assumption is that term, inflation and foreign exchange risk premia bave generally been so small as to warrant the use of forward rates as indicating expected future short rates, future inflation rates and future currency depreciation rates. This maintained assumption has some empirical support. Estimates of average forward premia for settlement in a few years and maturity one year later indicate that the premia are small. Also, the conventional wisdom that upward sloping yield curves imply positive term premia is not correct, since the upward sloping yield curve may be explained by expectations of rising short rates over the sample. However, according to the theory, it is actually conditional time-varying premia, rather than unconditional average premia that are relevant. More research on, and estimation of, conditional time-varying forward premia with for monetary policy relevant combinations of settlement and maturity is called for. Option prices on bond futures include information about perceived future interest rate volatility which can be used in estimating premia (cf. Bank of England (1994)). The literature has usually considered other term premia, the holding period and rollover term premia (defined in footnote 10 above), and other combinations of settlement and maturity. The literature has also frequently focused on testing the expectations hypothesis (the hypothesis of zero risk premia) rather than on actually estimating the size of the premia in order to judge whether the premia are economically as well as statistically significant. If conditional timevarying premia are non-negligible, that does not necessarily mean that forward rates cannot be used as indicators, only that the premia should be estimated simultaneously with the forward rates and then used to adjust the forward rates.

Availability of market real interest rates on indexed bonds with maturities between 2 and 10 years, as in Britain, would give increased precision to the interpretation of spot and forward rate movements for monetary policy purposes, especially during periods like the end of 1993 and the spring of 1994 when real rates may have been volatile.

\section{A. Appendix. Details on the estimation of forward rates}

For a given trade date, let there be $n$ coupon bonds $\left(c_{j}, m_{j}, y_{j}, p_{j}\right), j=1, \ldots, n$, where $c_{j}, m_{j}$, $y_{j}$ and $p_{j}$ denote, respectively, the coupon rate, the time to maturity, the observed yield to maturity and the observed price of bond $j$, which is assumed to have a face value of 100 units 
of domestic currency. (The bond prices are computed from the yields to maturity according to (2.3), or vice versa.) For a given parameter vector $b$ the estimated prices of the bonds, $P_{j}(b)$, are computed with the discount function $d(m ; b)$ in $(3.4)$ evaluating each coupon payment.

More precisely, for bonds with annual coupon payments, let $\tau_{j k}, k=1,2, \ldots, K_{j}$, denote the times to the coupon payments on bond $j$, where $K_{j}$ is the number of coupon payments. In the special case when $m_{j}$ is an integer, we simply have $\tau_{j k}=k$ and $K_{j}=m_{j}$. In the general case we have

$$
\begin{aligned}
\tau_{j k} & =m_{j}-\left[m_{j}\right]+k-1 \text { and } \\
K_{j} & =\left[m_{j}\right]+1,
\end{aligned}
$$

where $\left[m_{j}\right]$ denotes the largest integer that is strictly smaller than $m_{j}$. The estimated price of each bond, $P_{j}(b)$, is the present value of the bond when the coupon payments and the face value are priced with the discount function,

$$
P_{j}(b) \equiv \sum_{k=1}^{K_{j}} c_{j} d\left(\tau_{j k} ; b\right)+\operatorname{100d}\left(\tau_{j K} ; b\right), j=1, \ldots, n .
$$

For semiannual coupon payments, that is, for Britain and the United States, these relations are accordingly modified (see for instance Grave (1986)).

When price errors are minimized, the observed price is assumed to differ from the estimated price by an error term, $\epsilon_{j}$,

$$
p_{j}=P_{j}(b)+\epsilon_{j}
$$

The estimated prices are then fitted to the observed prices with Non-linear Least Squares, the General Method of Moments, or Maximum Likelihood. The estimates in this paper are Maximum Likelihood. The 95 percent confidence intervals have been computed with the delta method and are heteroskedasticity-consistent. ${ }^{19}$

When yield errors are minimized, the estimated yield to maturity for bond $j, Y_{j}(b)$, is computed from the observed bond price $P_{j}(b)$ by solving (2.3). Although (2.3) is a non-linear higher-order equation with the same order as the number of coupon payments, it has only one real root and is easy to solve numerically, for instance with the standard Newton-Raphson algorithm (see Gave (1986)). The observed yield to maturity is assumed to differ from the estimated yield to maturity by an error term,

$$
y_{j}=Y_{j}(b)+\epsilon_{j}
$$

\footnotetext{
${ }^{19}$ Let $\hat{b}$ and $\hat{L}$ denote the estimates of the parameter vector $b$ and its covariance matrix, respectively. The delta method implies that for the purpose of computing confidence intervals for the forward rate, the estimated forward rate $f(m ; b)$ for a given settlement $m$ is considered to be distributed as a Normal variable with mean $f(m ; \hat{b})$ and covariance $\frac{\partial f(m ; b)^{\prime}}{\partial b} L \frac{\partial f\left(m_{i} b\right)}{\delta b}$, where $\frac{\partial f\left(m_{;} b\right)}{\delta b}$ is the column vector of partial derivatives with respect to the parameters, etc.
} 
and the estimated yields to maturity are then fitted to the observed yields to maturity.

The estimation has been done with the restriction that the forward rate curve (and hence the spot rate curve) should start at the left end from the marginal lending rate or the overnight rate, except for Britain.

The difference between minimizing price and yield errors, and between the original and extended Nelson and Siegel functional form, is illustrated in Figures $1 \mathrm{~b}$ and Figures A1-A3.

Figure $A$ la shows the estimated spot and forward rate curves for December 29, 1993, when price errors are minimized with the original Nelson and Siegel functional form in (3.1). We see that the fit for the Treasury bill yields is unsatisfactory. Figure A1b shows estimated and observed prices. For the prices the fit is good. The estimated prices are close to the observed prices, and the error bars that denote 95 percent confidence intervals are hardly visible in the Figure. The root mean squared price error (RMSPE) is 0.18 kronor (for bonds with face value 100 kronor), whereas the root mean squared yield error (RMSYE) is 0.22 percentage points. The maximum absolute yield error is 0.57 percentage points and occurs for the 3 -month Treasury bill.

Figure A2a shows the estimated spot and forward rate curves for the same trade date, when instead yield errors are minimized, still with the original Nelson and Siegel functional form. The RMSYE has fallen to 0.16 percentage points. The maximum absolute yield error has fallen to 0.38 percentage points and still occurs for the 3 -month Treasury bill. The fit for the yields is still hardly satisfactory. The confidence intervals for the forward rates are rather large. The RMSPE has increased to 0.51 kronor. We see in Figure $A 2 b$ that the fit for prices is worse than in Figure $A 1 b$, and that the confidence intervals are larger.

Figure $1 \mathrm{~b}$ shows the estimated spot and forward rates when yield errors are minimized and when the extended Nelson and Siegel functional form is used. Figure $A 3$ shows the corresponding observed and estimated prices. The fit is quite good both for yields and prices. The RMSYE is only 0.03 percentage points, and the RMSPE is 0.16 kronor. The maximum absolute yield error is $\mathbf{0 . 0 5}$ percentage points and occurs for the12-month Treasury bill. It is evident from Figure 1 that the second $U$-shape (the thin solid line) allows a much better fit at the short end of the spot rate curve.

The term structure on December 29 is unusually complex. In most cases the original Nelson and Siegel functional form with minimized yield errors gives a satisfactory result, and in quite a few cases the difference between the estimates for minimized yield errors and minimized price errors is small.

\section{References}

Aragon (1994), Press Release, May 10, 1994, Aragon Securities Fondkommision AB. 
Bank of England (1993a), Inflation Report, May 1993.

Bank of England (1993b), Inflation Report, August 1993.

Bank of England (1994), Inflation Report, May 1994.

Bank for International Settlements (1993), 63rd Annual Report, Basle.

Campbell, John Y., and Robert J. Shiller (1991), "Yield Spreads and Interest Rate Movements: A Bird's Eye View," Review of Economic Studies 58, 495-514.

Dahlquist, Magnus, and Lars E. O. Svensson (1994), "Estimation of the Term Structure of Interest Rates with Simple and Complex Functional Forms: Nelson \& Siegel vs. Longstaff \& Schwartz," IIES Seminar Paper No. 565.

Fage, Paul (1986), Yield Calculations, Credit Suisse First Boston, London.

Fama, Eugene F., and Robert R. Bliss (1987), "The Information in Long-Maturity Forward Rates," American Economic Review 77, 608-692.

Fisher, Mark E., Douglas Nychka and David Zervos (1994), "Fitting the Term Structure of Interest Rates with Smoothing Splines," Working Paper, Board of Governors of the Federal Reserve System.

Hodrick, Robert J., (1987), The Empirical Evidence on the Efficiency of Forward and Futures Foreign Exchange Markets, Harwood Academic Publishers, London.

Hörngren, Lars, and Hans Lindberg (1993), “The Struggle to Turn the Swedish Krona into a Hard Currency," Working Paper No. 8, Sveriges Riksbank.

Longstaff, Francis A., and Eduardo S. Schwartz (1992), "Interest Rate Volatility and the Term Structure: A Two-Factor General Equilibrium Model," Journal of Finance 47, 1259-1282.

Marston, Richard C. (1993), "Nominal Interest Differentials," manuscript chapter.

McCulloch, J. Huston (1971), "Measuring the Term Structure of Interest Rates," Journal of Business 44, 19-31.

McCulloch, J. Huston (1975), "An Estimate of the Liquidity Premium," Journal of Political Economy 83, 62-63.

McCulloch, J. Huston (1990), "US Term Structure Data, 1946-1987," Appendix B in Shiller (1990). 
Nelson Charles R., and Andrew F. Siegel (1987), "Parsimonious Modeling of Yield Curves," Journal of Business 60, 473-489.

Reinhart, Vincent, and Leora Klapper (1992), "Understanding the Simple Algebra of Forward Rates," Working Paper, Board of Governors of the Federal Reserve System.

Shea, Gary S. (1984), "Pitfalls in Smoothing Interest Rate Term Structure Data: Equilibrium Models and Spline Approximations," Journal of Financial and Quantitative Analysis 19, 253-269.

Shiller, Robert J. (1990), "The Term Structure of Interest Rates," Chapt. 13 in Friedman, Ben M., and Frank H. Hahn (eds), Handbook of Monetary Economics, Volume I, North-Holland, Amsterdam.

Svensson, Lars E.O. (1993b), "The Forward Interest Rate Curve - An Indicator of Market Expectations of Future Interest Rates, Inflation and Exchange Rates" (in Swedish), Ekonomisk Debatt 21-3, 219-234.

Svensson, Lars E.O. (1993c), "Monetary Policy with Flexible Exchange Rates and Forward Interest Rates as Indicators, "IIES Seminar Paper No. 559. Cahiers Économiques et Monétaires, Banque de France, forthcoming.

Svensson, Lars E.O. (1993d), "Term, Inflation and Foreign Exchange Risk Premia: A Unified Treatment," IIES Seminar Paper No. 548.

Sveriges Riksbank (1993a), Inflation and Inflation Expectations, October 1993.

Sveriges Riksbank (1993b), Monetary Policy Indicators, June 1993. 


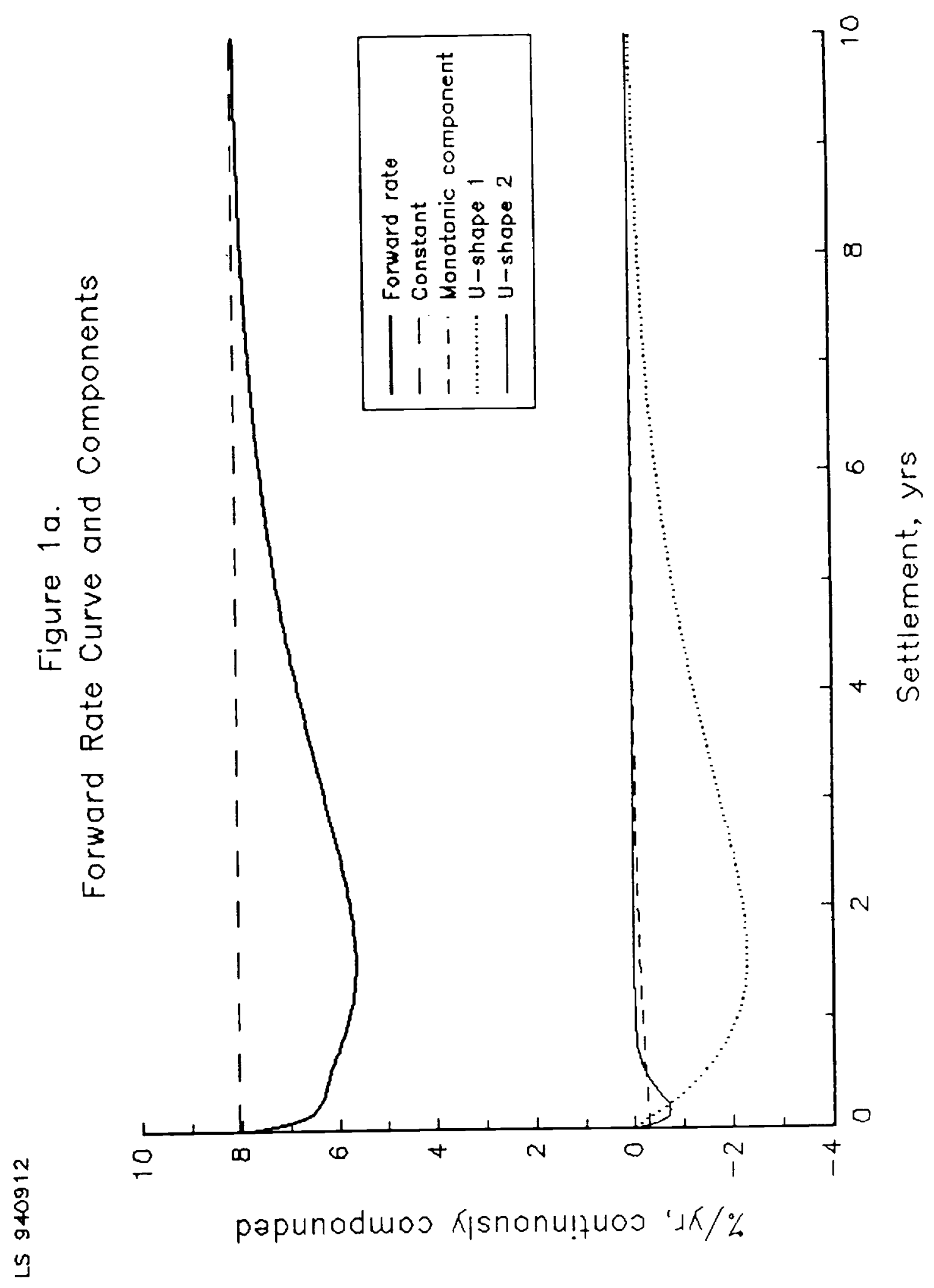




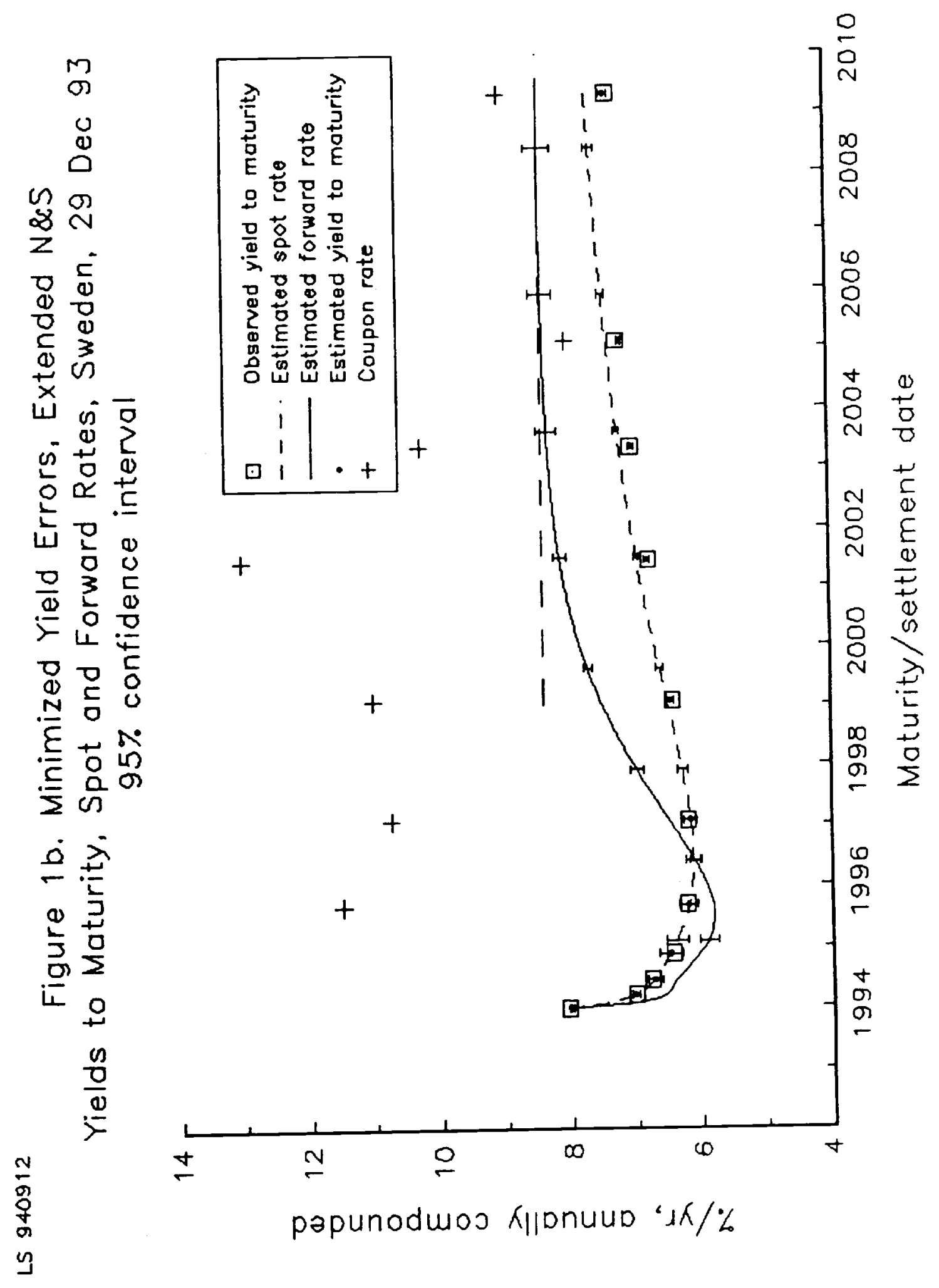




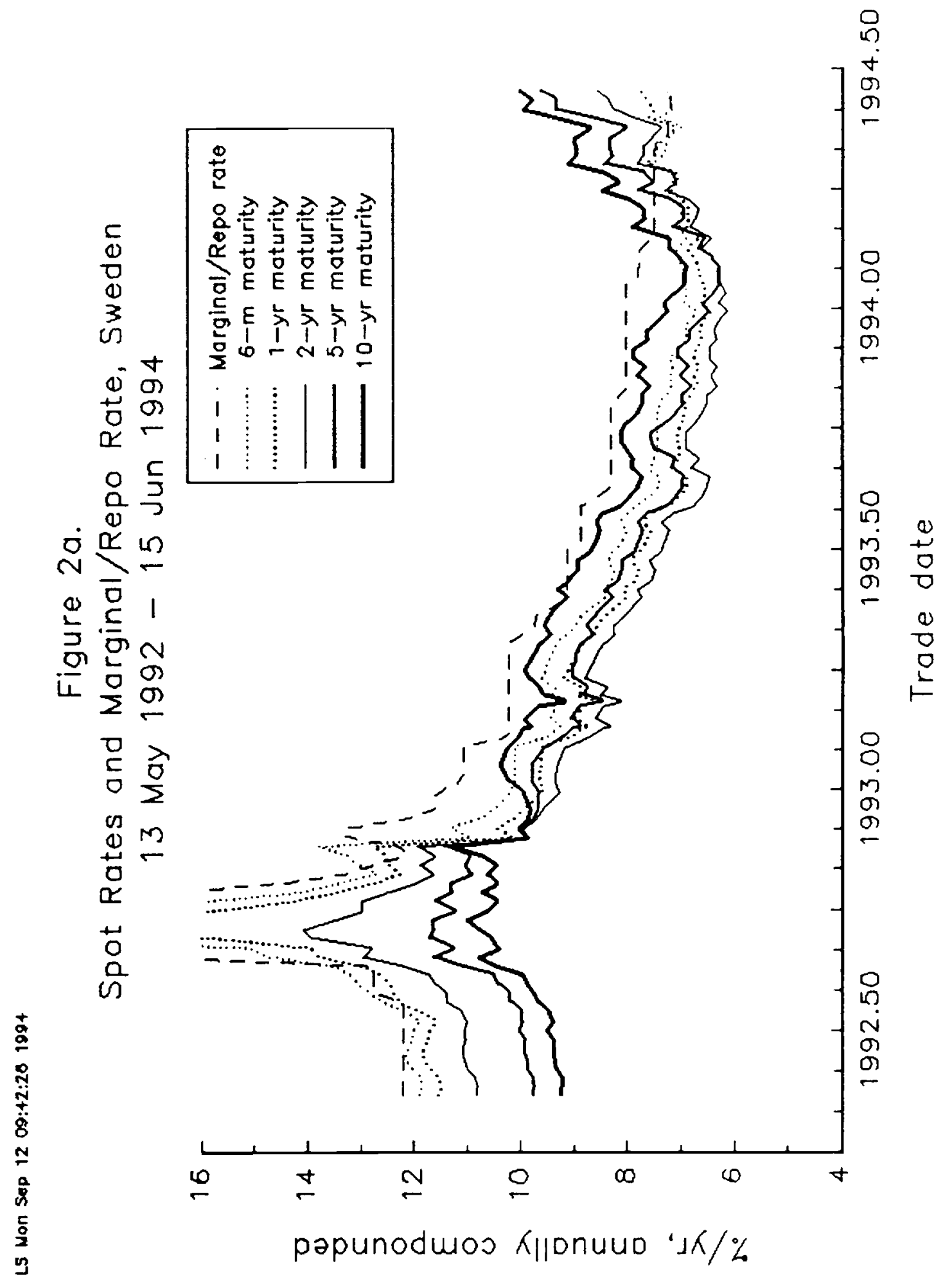




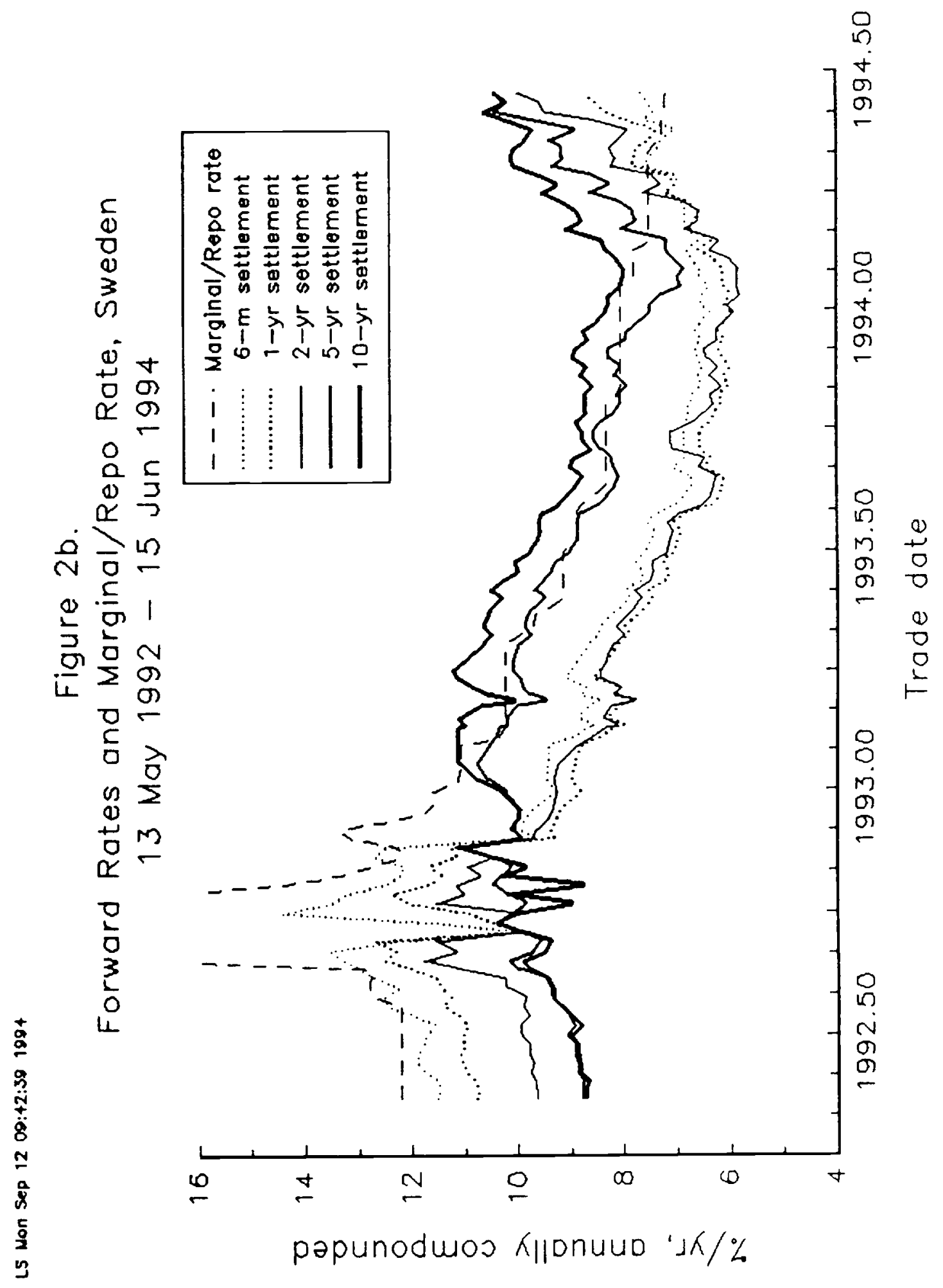




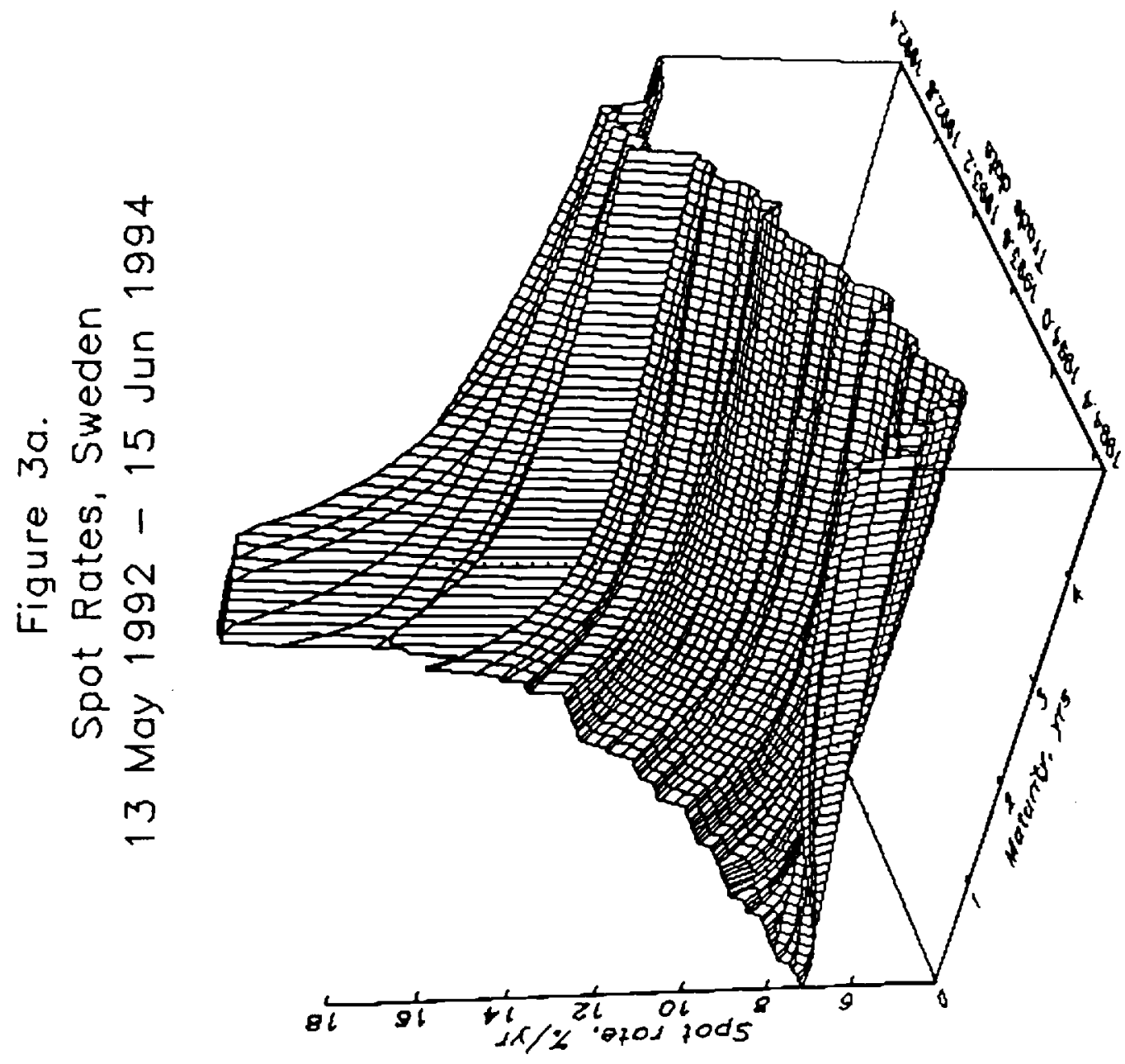

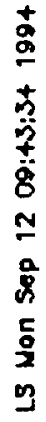




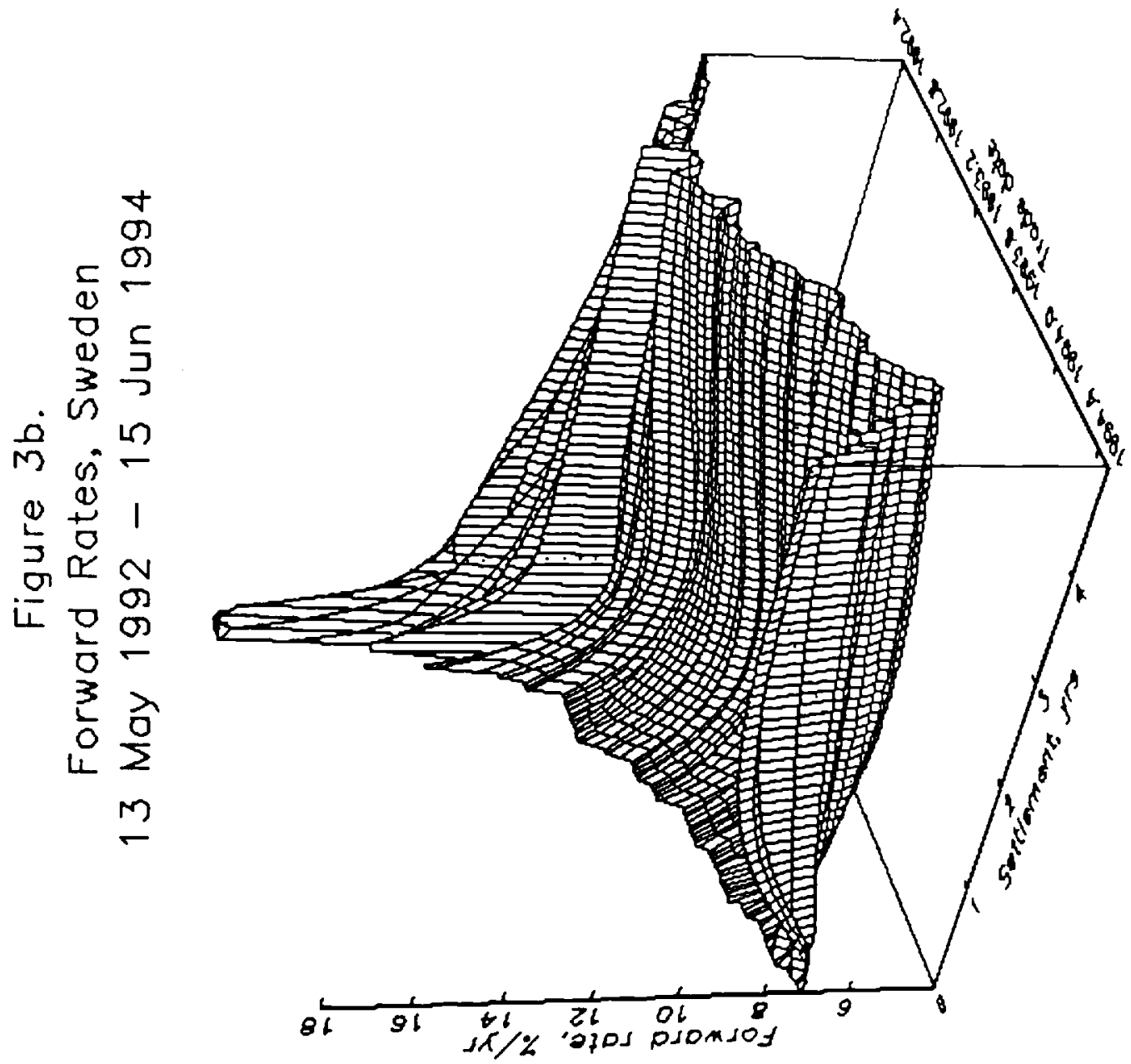

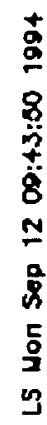




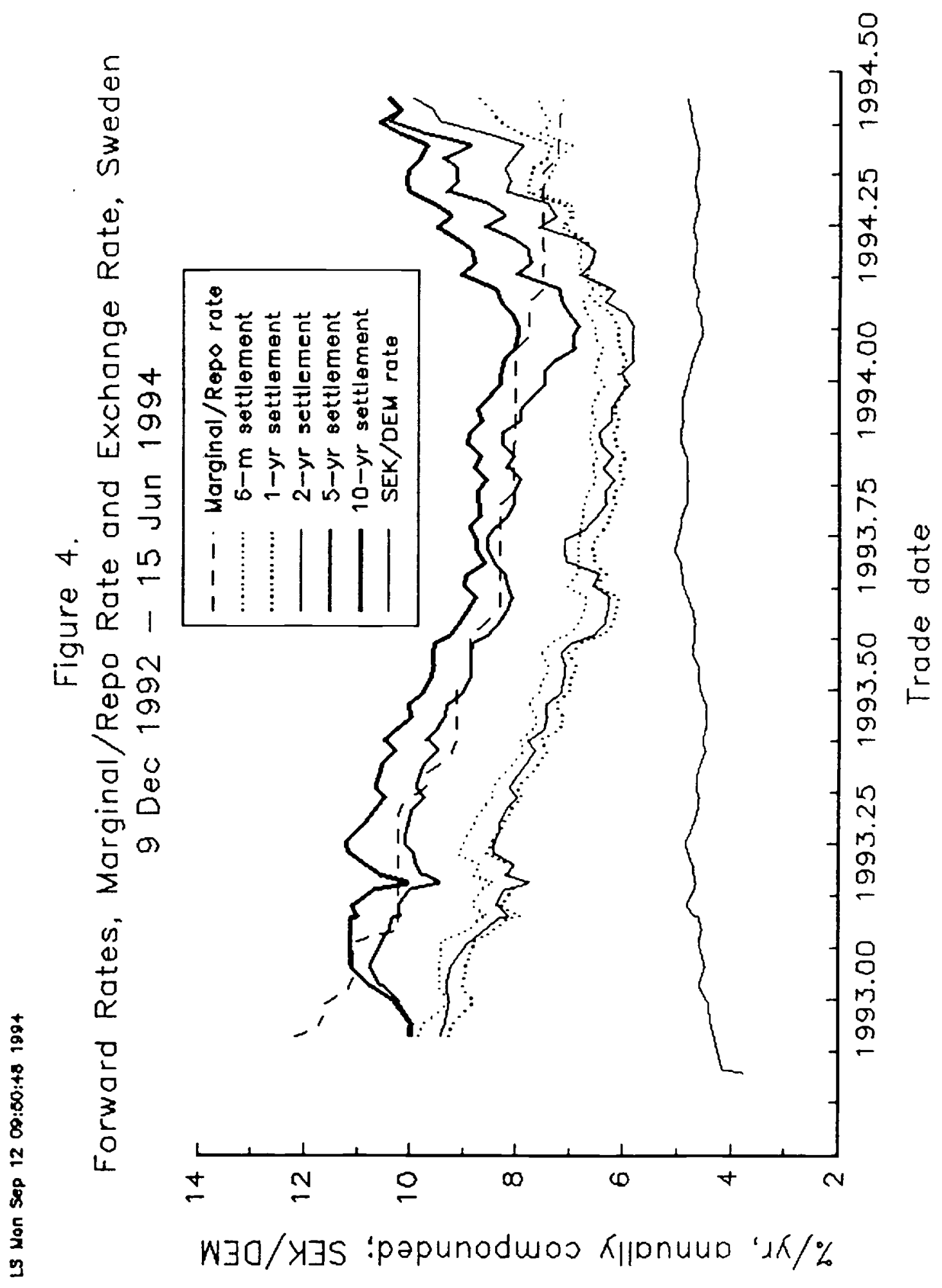




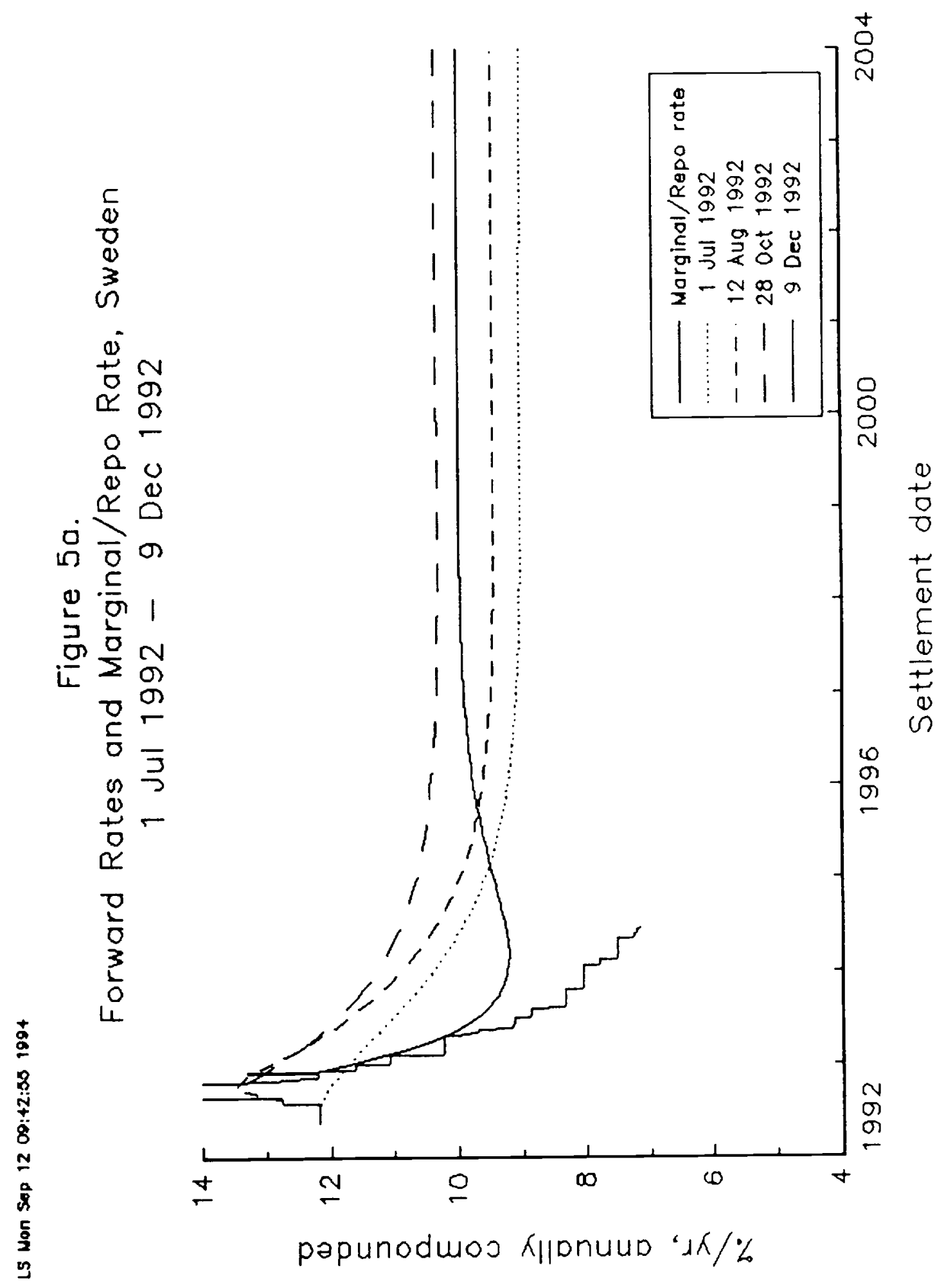




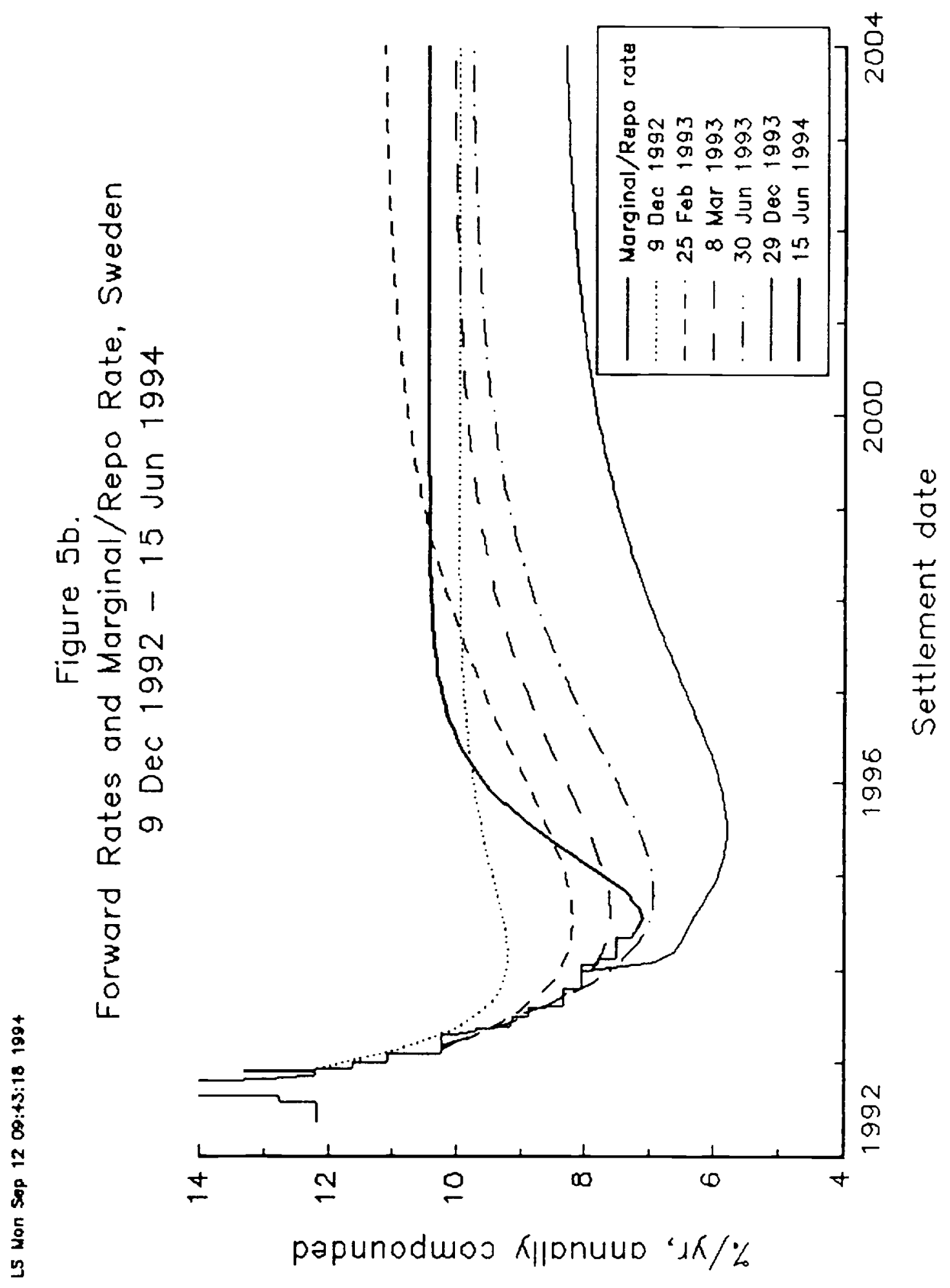




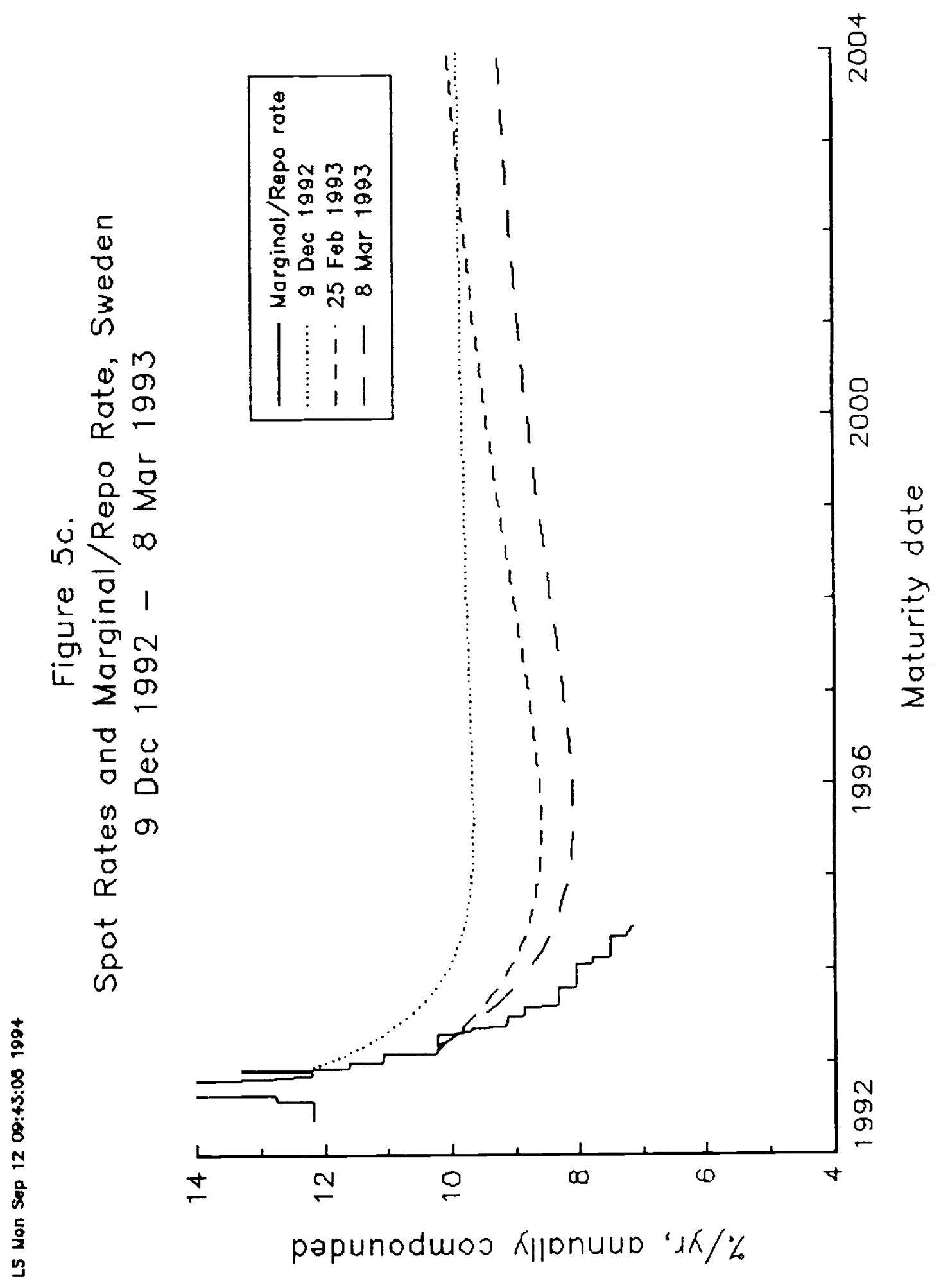




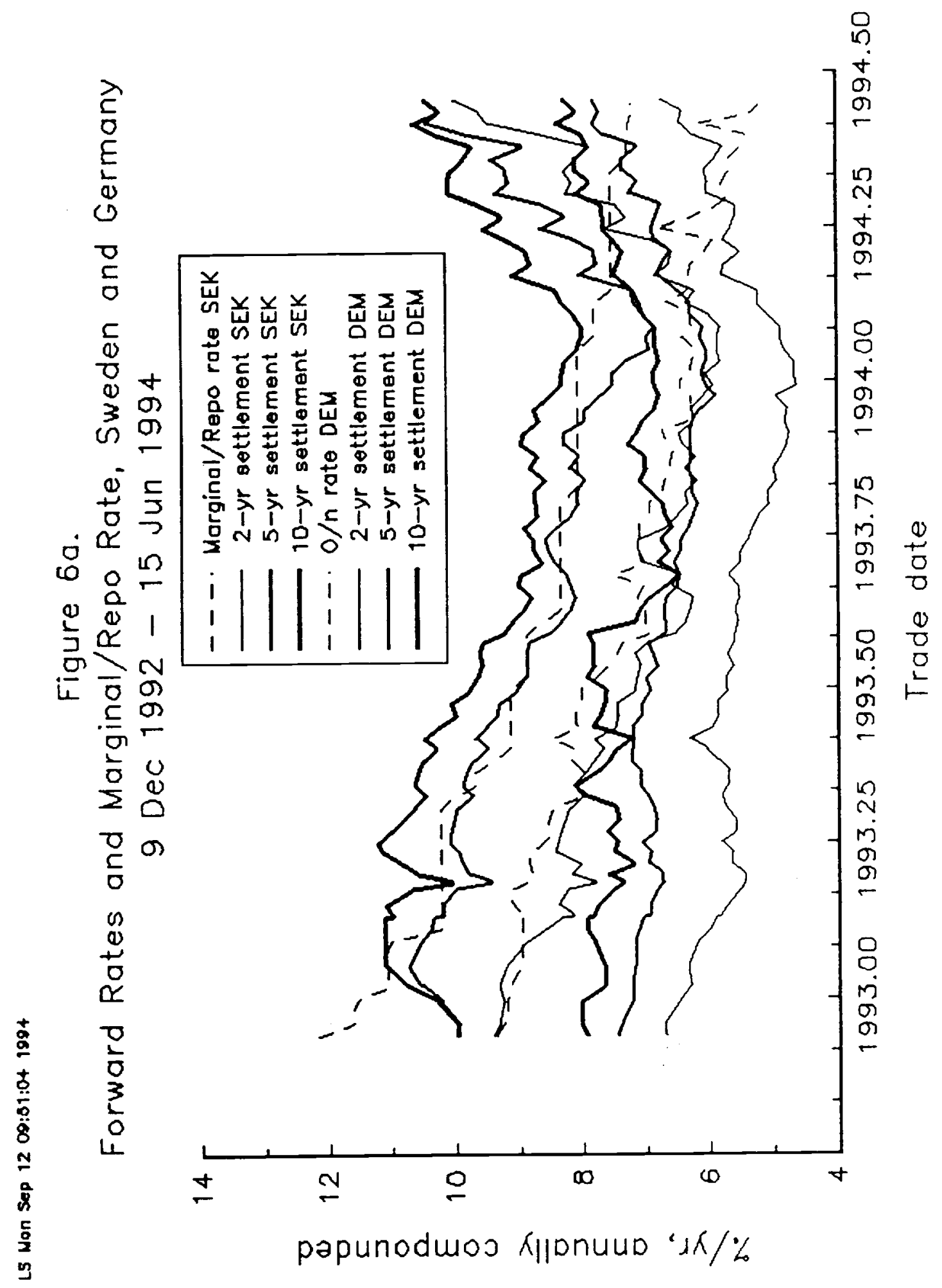




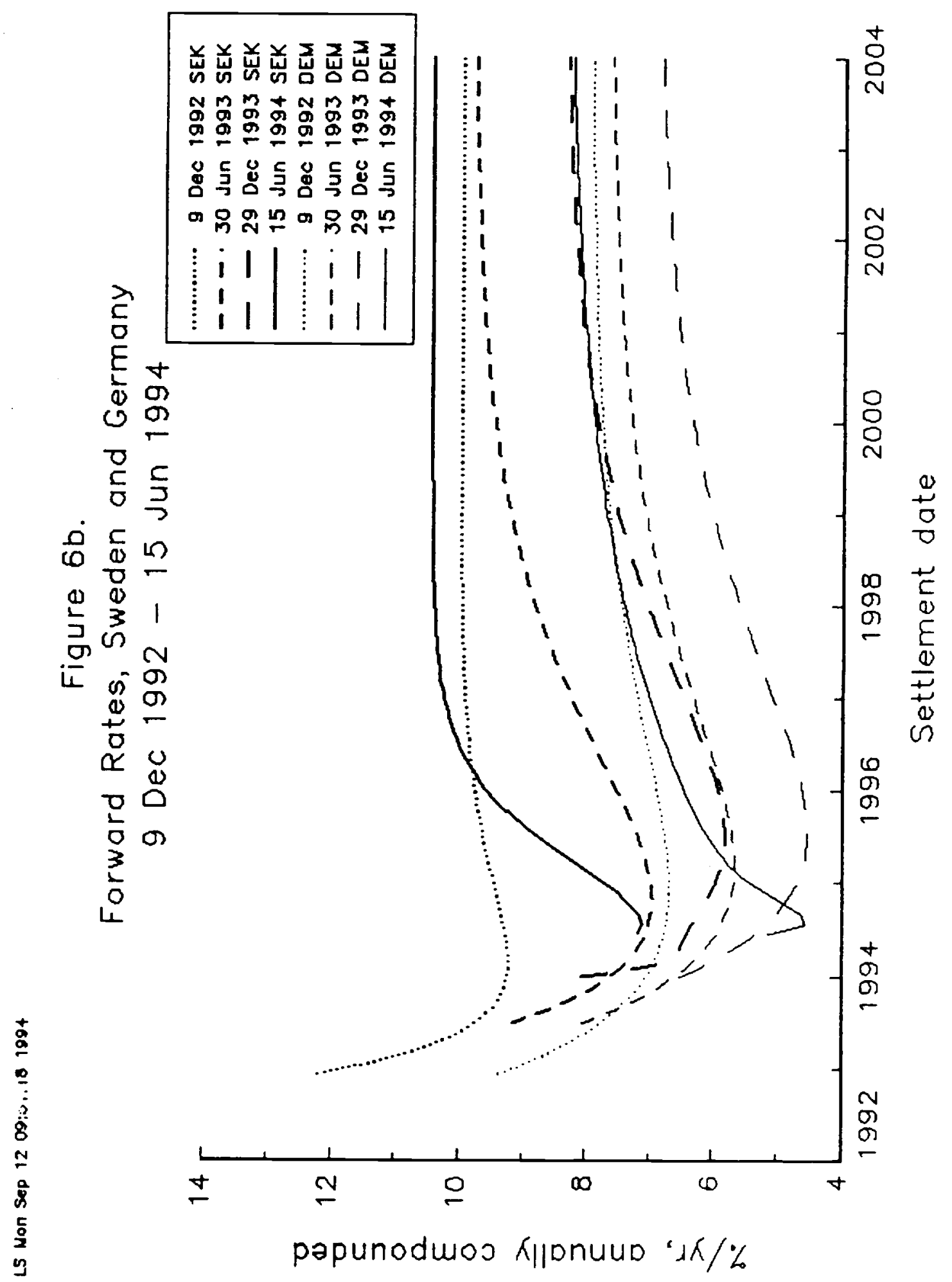




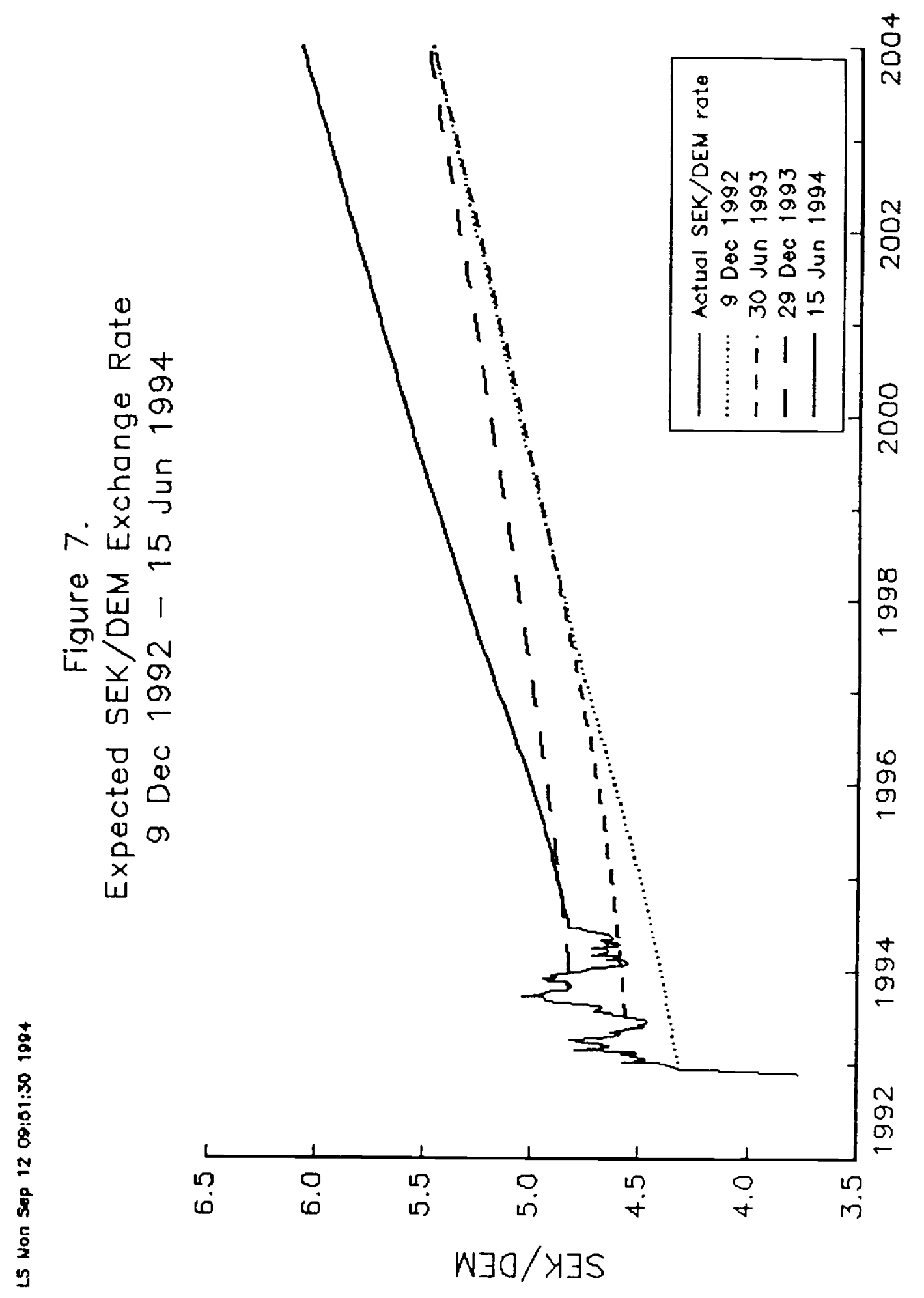


Figure 8a. Forward Rates by Trade Dote 30 Jun 1993

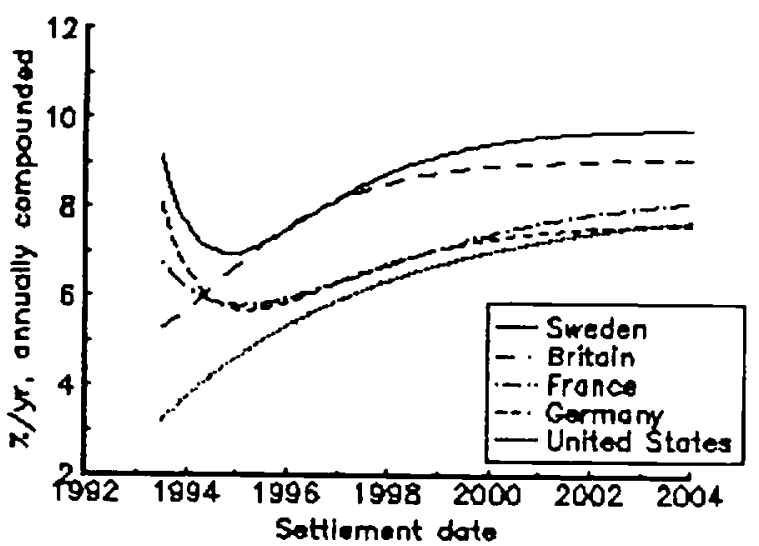

29 Dec 1993

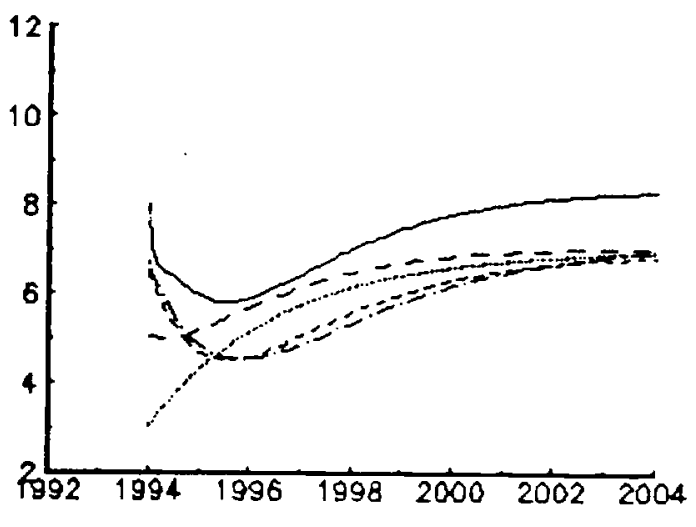

15 Jun 1994

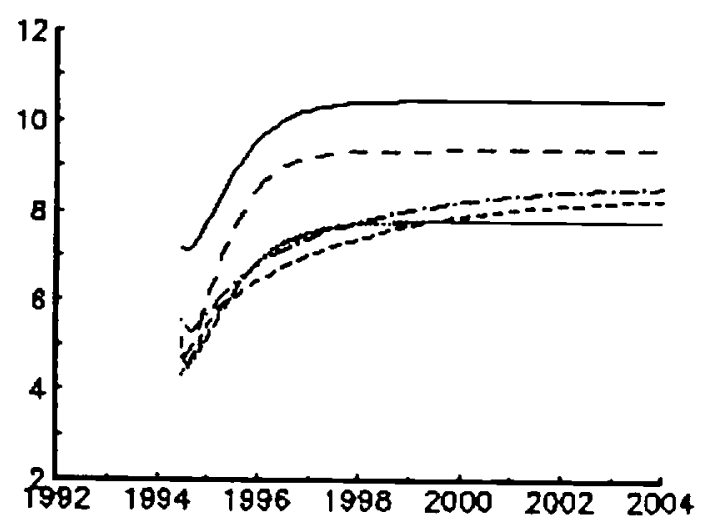


Figure 8b. Spot Rates by Trade Date

30 Jun 1993

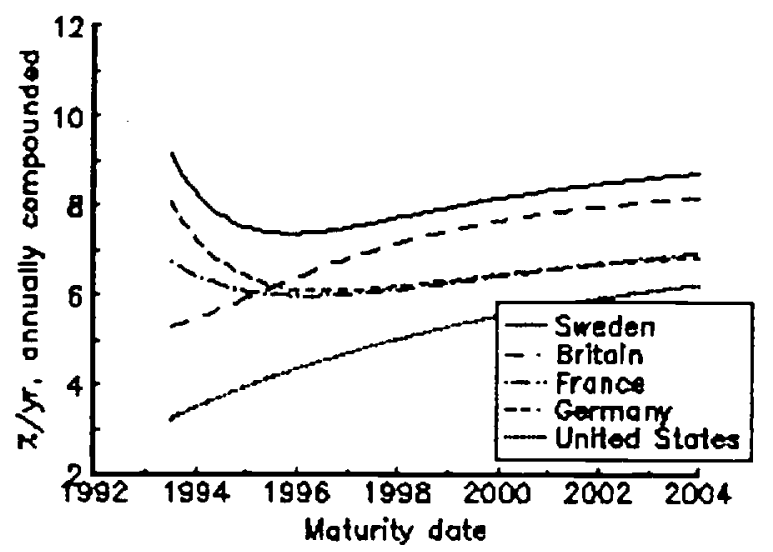

15 Jun 1994

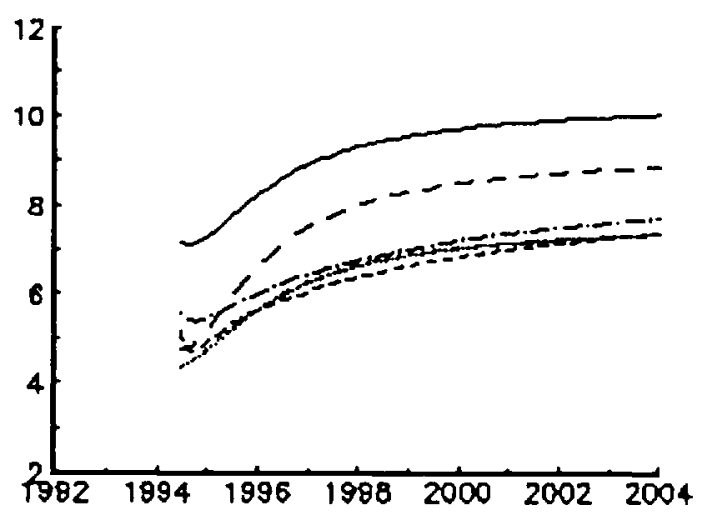

29 Dec 1993

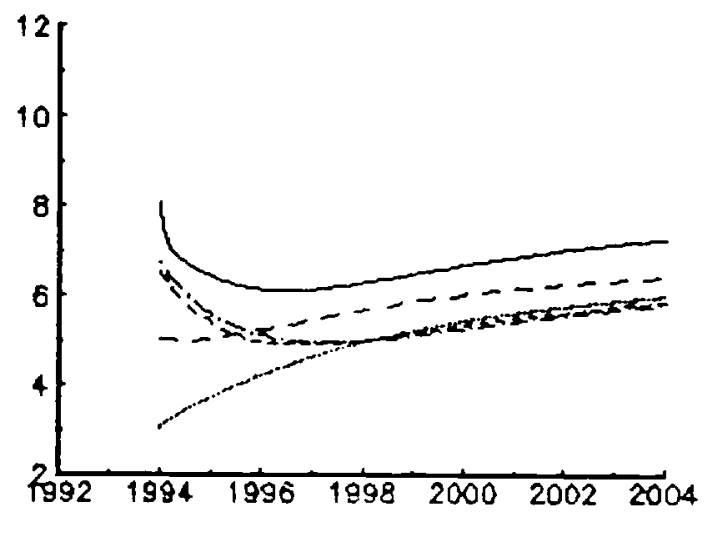




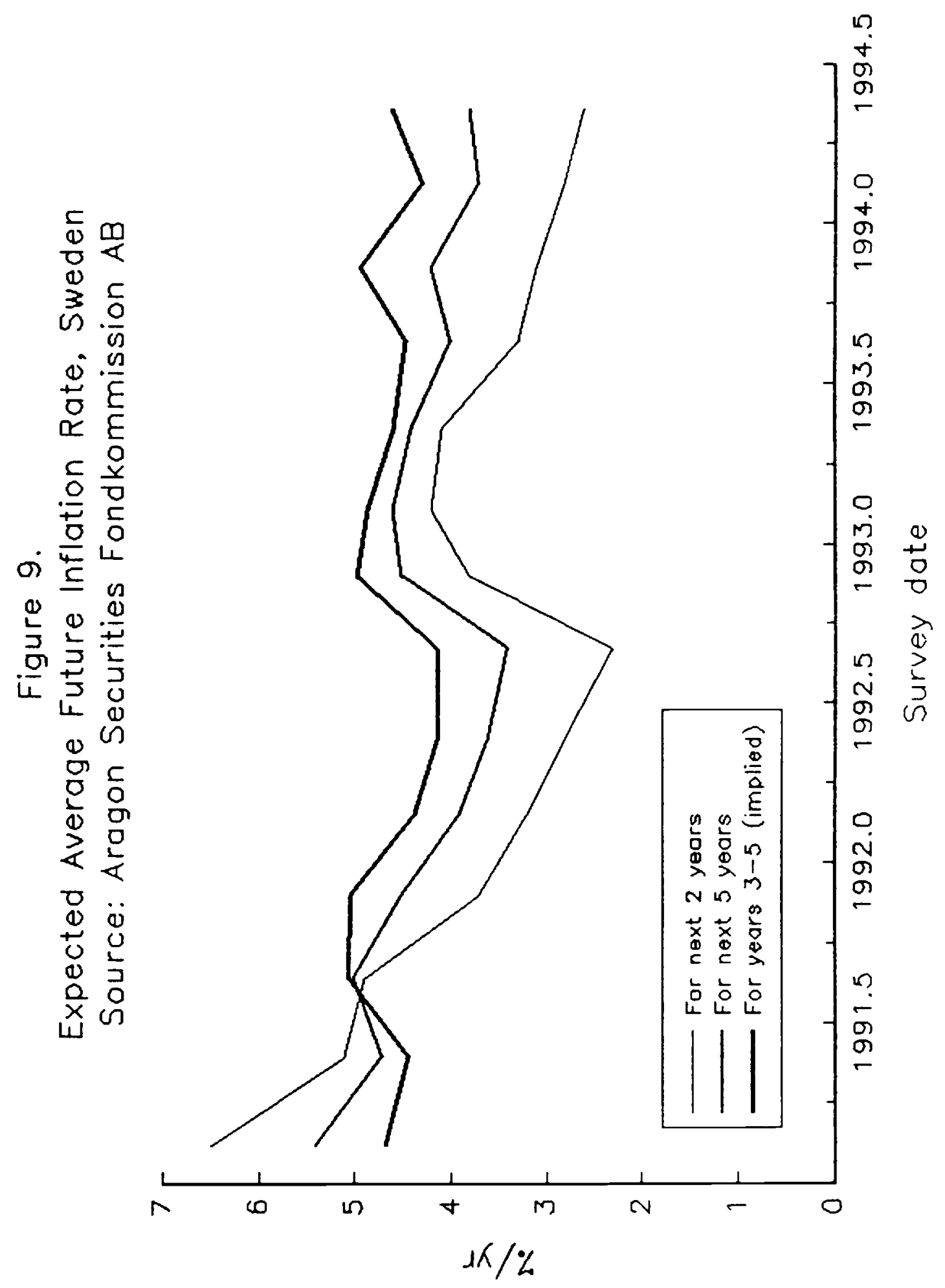




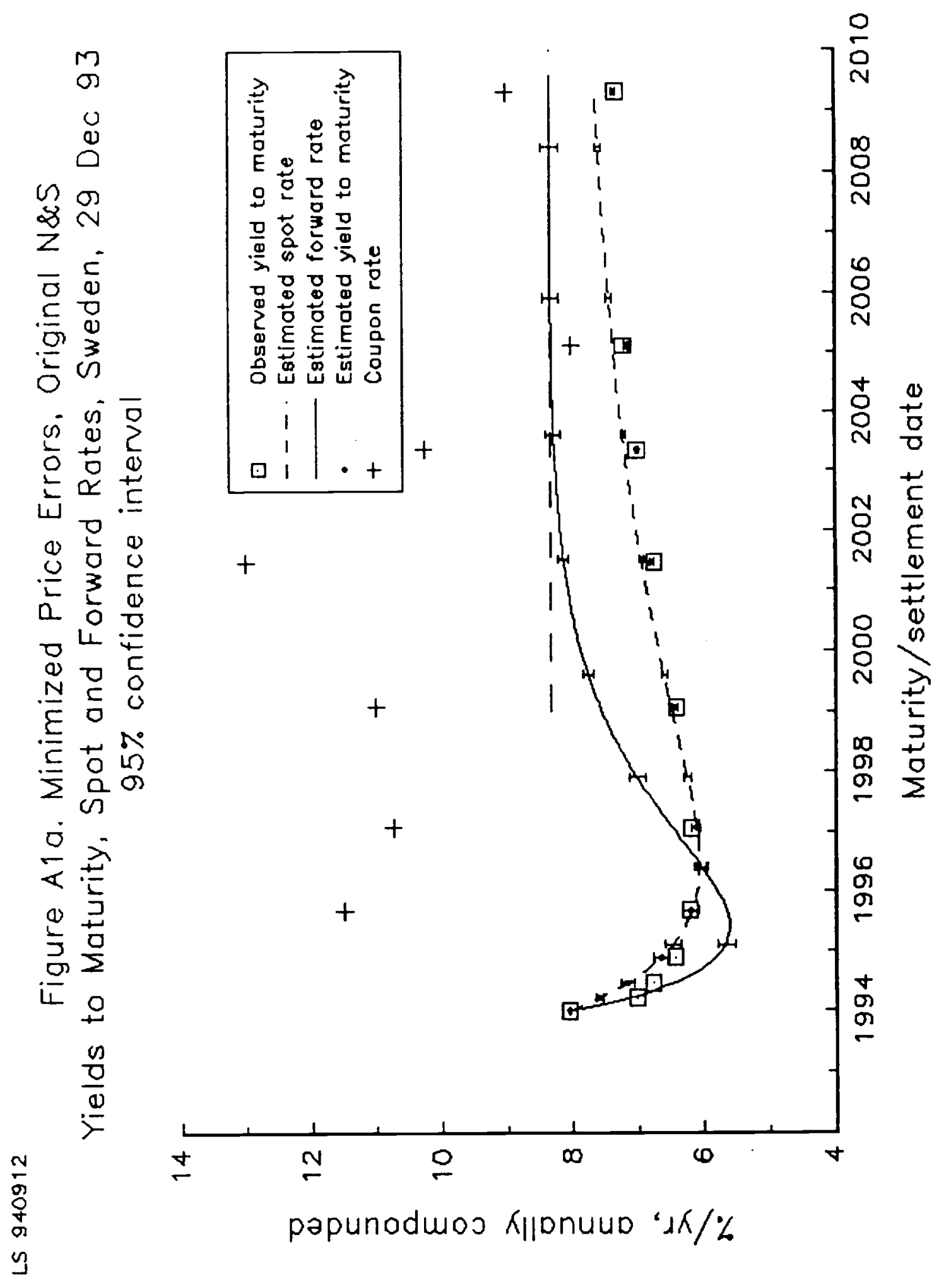




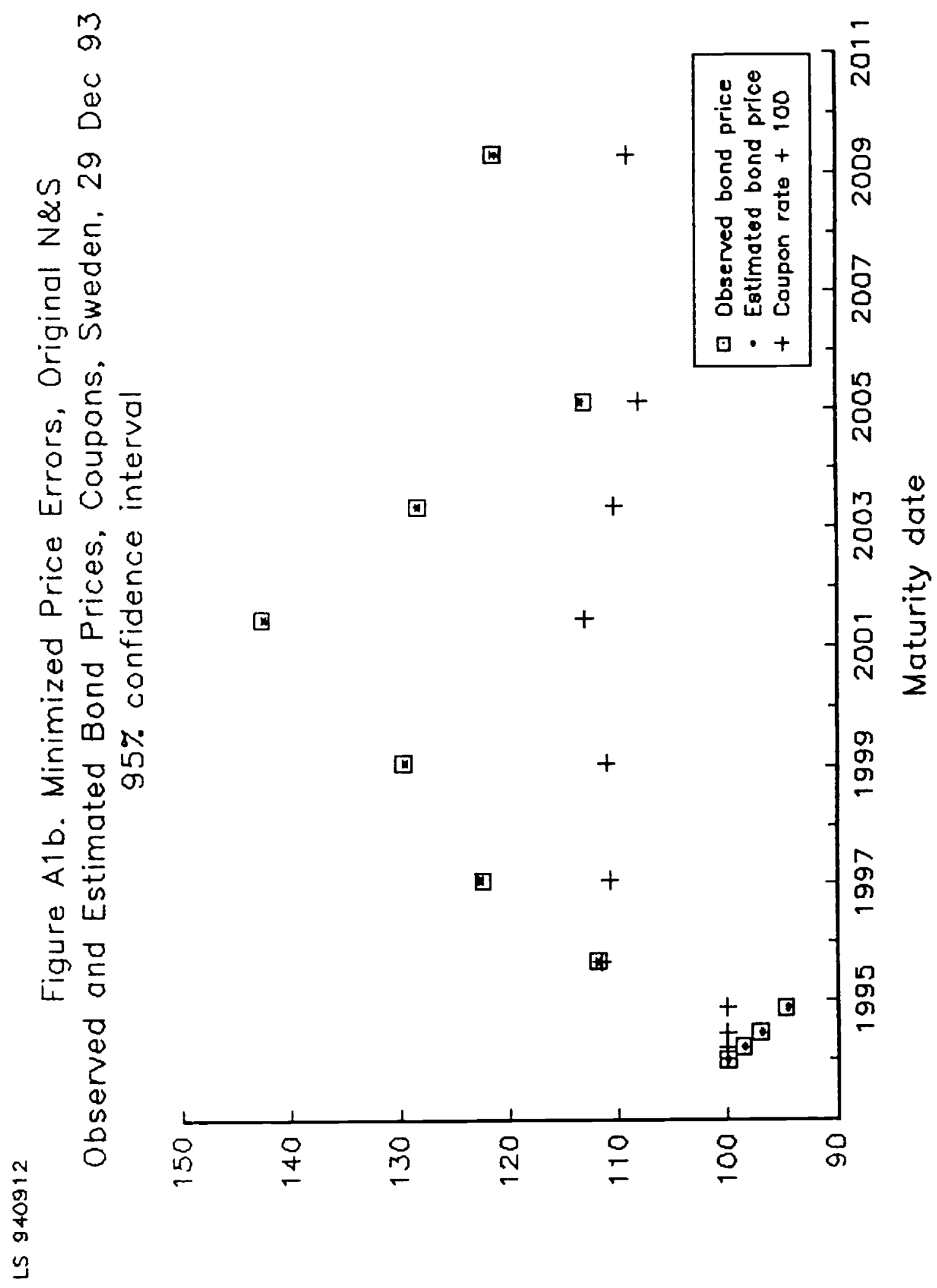




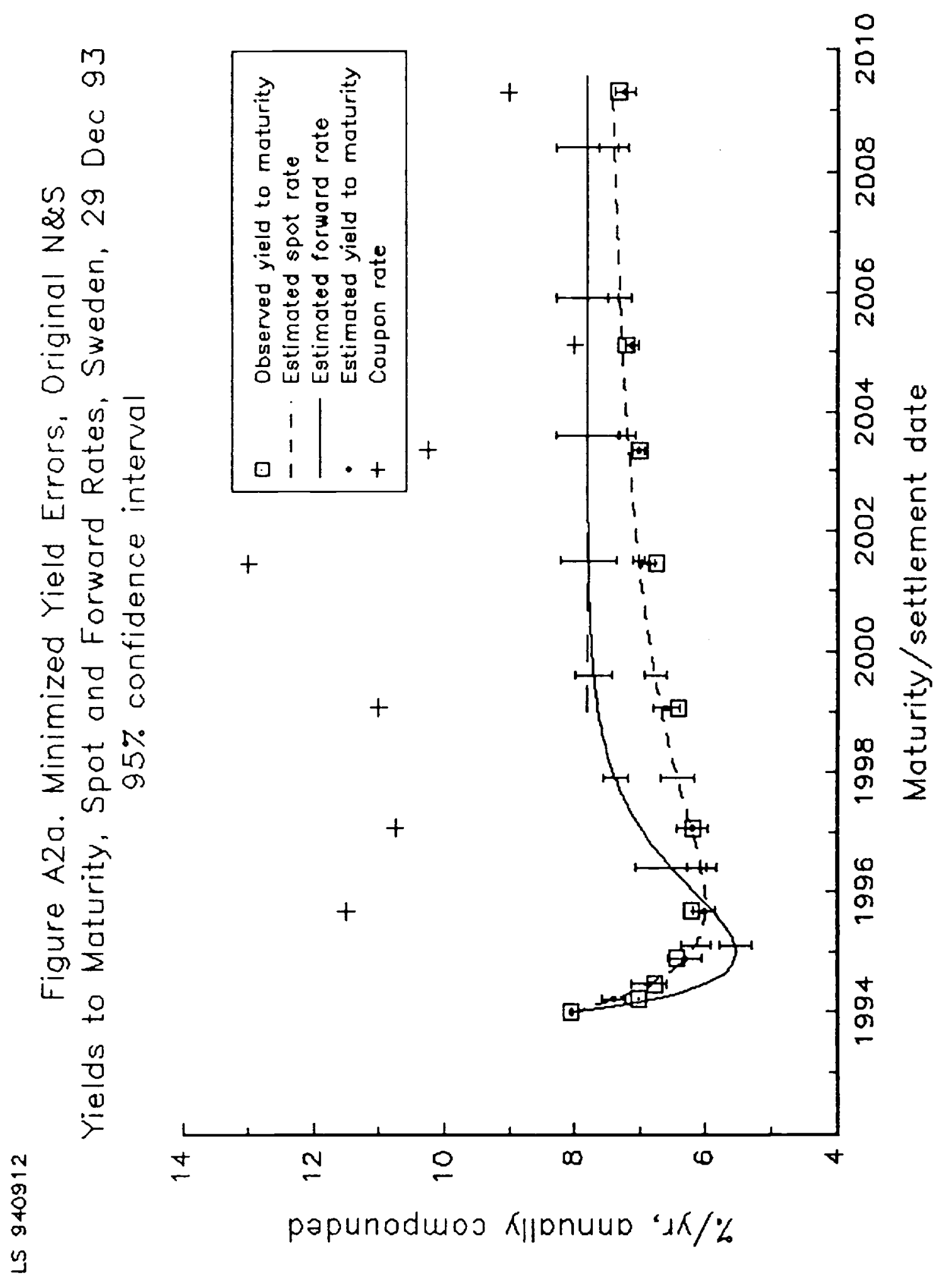




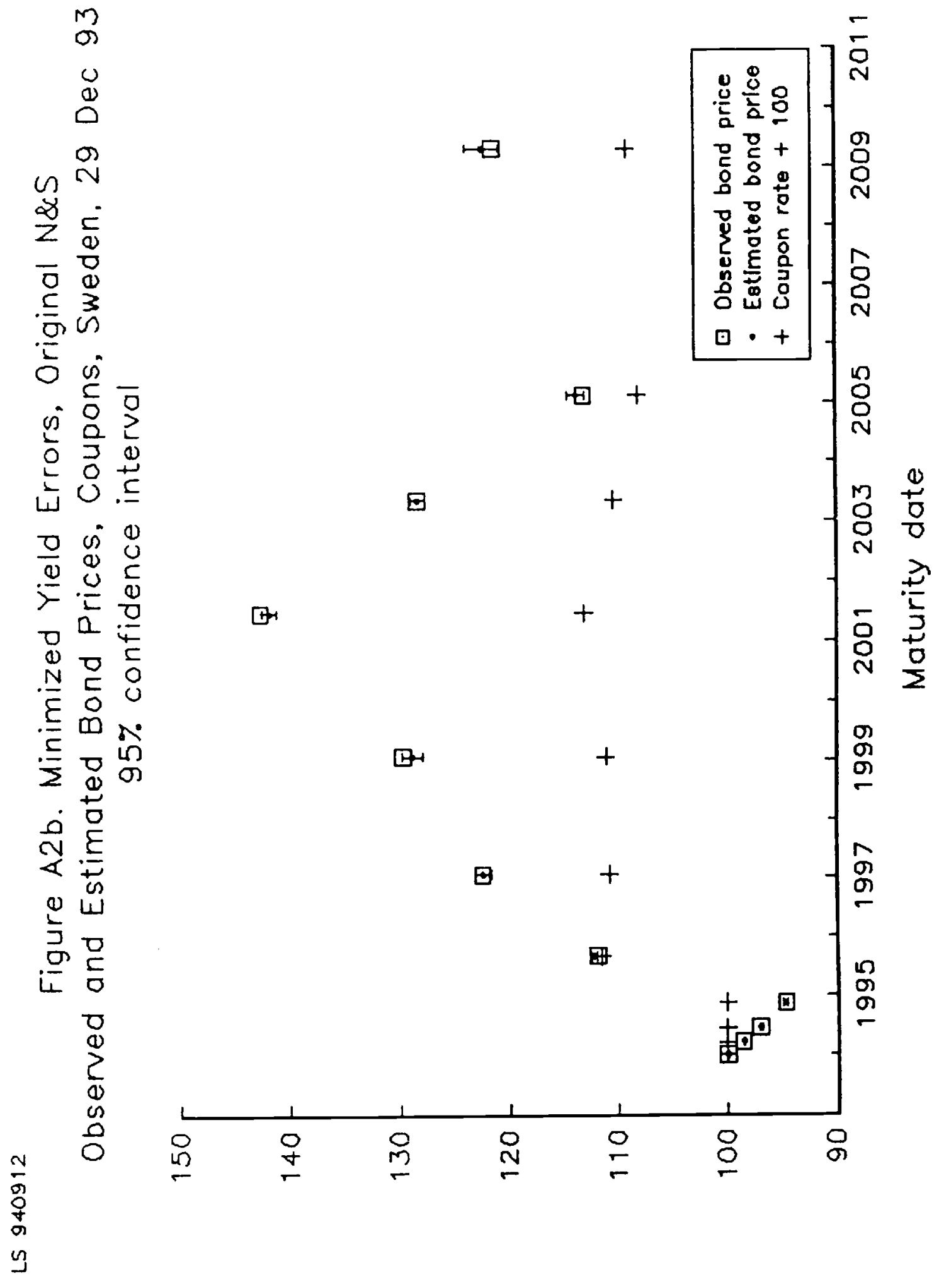




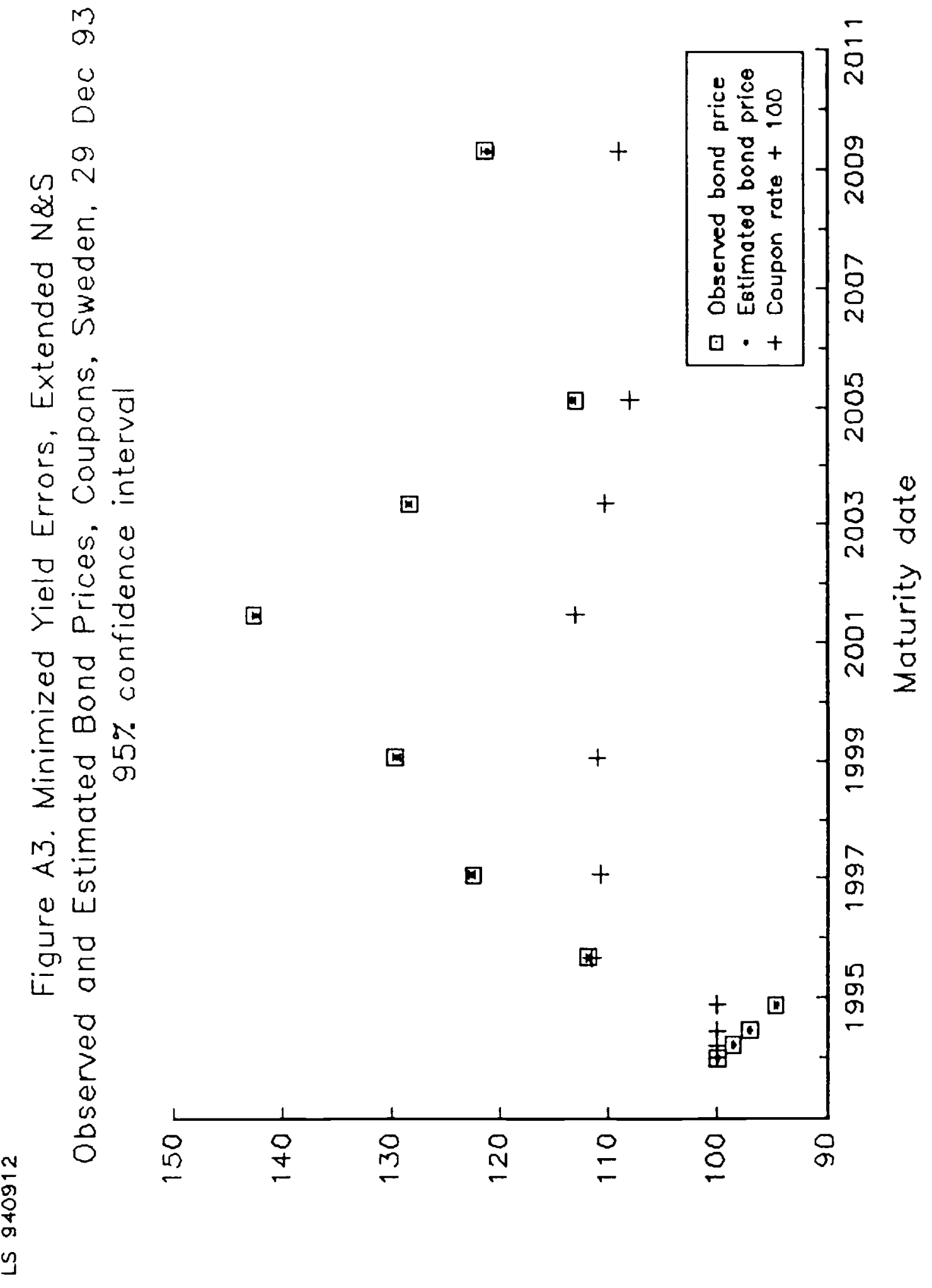

